\title{
Osthole Regulates Secretion of Pro-Inflammatory Cytokines and Expression of TLR2 and NF-KB in Normal Human Keratinocytes and Fibroblasts
}

\author{
Natalia Kordulewska', Justyna Topa ${ }^{2}$, Anna Cieślińska $\mathbb{D}^{\prime}$, Beata Jarmołowska' \\ 'Department of Biochemistry, Faculty of Biology and Biotechnology, University of Warmia and Mazury, Olsztyn, Poland; ${ }^{2}$ Laboratory of Translational \\ Oncology, Intercollegiate Faculty of Biotechnology, Medical University of Gdańsk, Gdańsk, Poland \\ Correspondence: Natalia Kordulewska, Tel + 4889523 37 63, Fax + 488953520 15, Email natalia.smulska@uwm.edu.pl
}

\begin{abstract}
Introduction: Osthole (OST), an active compound isolated from Cnidium monnieri, is used in traditional Chinese medicine to treat a variety of human diseases. Although OST has a good therapeutic effect, the underlying mechanism of its action in inflammatory skin diseases in humans is still unknown.

Purpose: The present study aimed to test the hypothesis that OST can be used as an herbal substance that minimizes skin inflammation and barrier dysfunction. In this study, histamine and LPS were used to induce inflammation in skin keratinocytes and fibroblasts to test whether OST can inhibit their responses.

Methods: Cell migration was analyzed using a wound healing assay. Changes in cell monolayer integrity were assessed by the measurement of transepithelial electrical resistance. Secretion of IL-1 $\beta$, IL-6, IL-8, TNF- $\alpha$, CCL2/MCP-1, CCL5/RANTES, and COX-2 was measured by ELISA, while expression of $T L R 2, N F-\kappa B$, and $C O X-2$ was analyzed by qPCR.

Results: OST decreased the level of IL-1 $\beta$, TNF- $\alpha$, CCL2/MCP-1 and CCL5/RANTES, and expression of TLR2, NF- $\kappa B$ and COX-2 during histamine/LPS-induced inflammation in human keratinocytes and fibroblasts. OST also improved cell migration and cell barrier function.

Conclusion: Our results suggest that OST suppresses inflammatory responses via regulation of IL-1 $\beta$, TNF- $\alpha$, CCL2/MCP-1 and CCL5/RANTES secretion, and TLR2, and COX-2 expression.
\end{abstract}

Keywords: pro-inflammatory cytokines, keratinocytes, fibroblasts, clobetasol propionate, fexofenadine

\section{Introduction}

Osthole (OST) (7-methoxy-8-(3-methyl-2-butenyl)coumarin) is a natural compound isolated from Cnidium plants and commonly used in Chinese medicine to improve immune system functions. ${ }^{1}$ OST possesses a broad spectrum of pharmacological properties: anti-allergic, ${ }^{2}$ anti-inflammatory, ${ }^{2}$ anti-tumor, ${ }^{3-5}$ hepatoprotective, ${ }^{6-8}$ neuroprotective ${ }^{9,10}$ and osteoprotective. ${ }^{11}$ In our previous research, we have shown that OST exhibits anti-inflammatory effects in peripheral blood mononuclear cells (PBMCs) isolated from children with autism spectrum disorder and diagnosed allergy or asthma. $^{2,12-17}$ In the model of human colon epithelium co-cultured with neutrophils or macrophages, the antiinflammatory effects of OST were confirmed by changes in the expression of inflammation-associated genes and proteins. ${ }^{18}$ However, its anti-inflammatory properties in inflammatory skin diseases have not yet been demonstrated.

The skin is the main barrier protecting from inflammation as it is composed of different cell types that respond to bacterial pathogenic factors (lipopolysaccharide - LPS, other pathogenic lipoproteins or peptides) and trigger inflammatory responses ${ }^{19-21}$ In recent years, keratinocytes have been shown to play an active role in the development and expression of protective immune responses and immunopathological reactions in the skin. ${ }^{22}$ In keratinocytes stimulated by environmental, physical or chemical stimuli, a release of proinflammatory mediators is observed in vitro and in vivo. ${ }^{23}$ 


\section{Graphical Abstract}

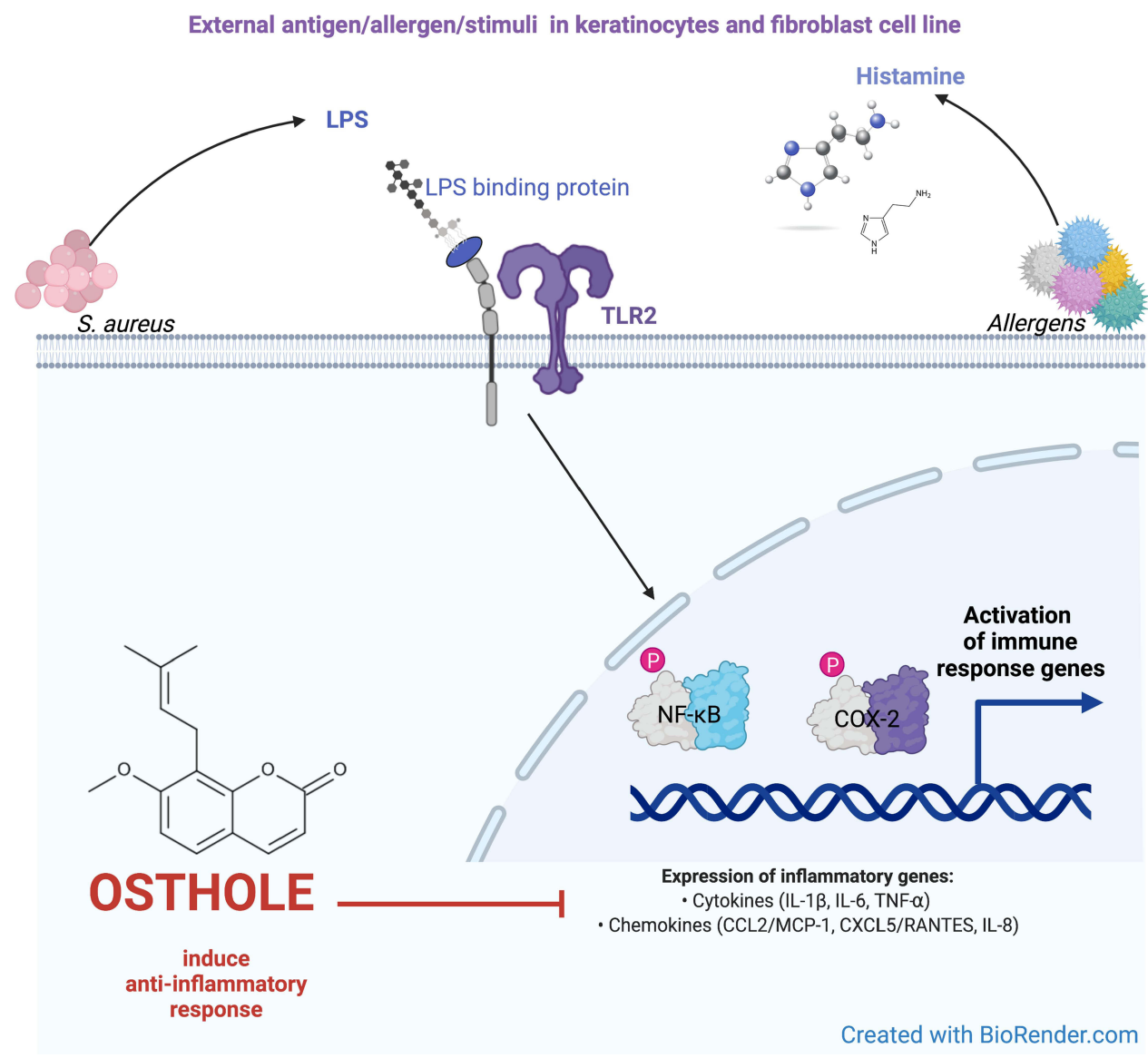

Fibroblasts, identified as a cells responsible for the production and organization of the extracellular matrix, are also considered as an active players of the immune system. ${ }^{24,25}$

Inflammation is associated with the development of skin diseases, ${ }^{26,27}$ and histamine is a known mediator of acute inflammation and immediate hypersensitivity reactions. ${ }^{28}$ Histamine is released by mast cells located in upper dermis, when tissues are inflamed or stimulated by allergens or LPS. ${ }^{29}$ Elevated histamine level has been described in eczematous skin disease and psoriasis, and can reach concentrations as high as approximately $100 \mu \mathrm{g} / \mathrm{mL}$ during immediate hypersensitivity reactions following mast cell degranulation. ${ }^{30}$ In addition to its involvement in immediate-type allergies and dendritic cell maturation, histamine also stimulates human keratinocytes via histamine receptors to increase the expression of antimicrobial peptides, cytokines (CKs), chemokines (ChKs), and matrix metalloproteinases. ${ }^{31,32}$ Mast cell activation and histamine release also contribute to skin barrier dysfunction in inflammatory skin diseases. ${ }^{33}$

The above findings led to use histamine and LPS to stimulate inflammation in human keratinocyte and fibroblast cell lines. In order to compare the effect of OST as a substance counteracting the immune overactivity of the skin caused by histaminic or bacterial inflammation, the cells were stimulated with clobetasol propionate (CP) - glucocorticosteroid, and fexofenadine (FXF), a selective histamine $\mathrm{H} 1$ receptor antagonist.

This study involves the analysis of the anti-inflammatory properties of OST in normal human epithelial keratinocytes (NHEK) and normal human dermal fibroblasts (NHDF) cell lines. These cell lines were selected to analyze the response of skin components to the tested substance under inflammatory conditions and to compare its effect with drugs commonly used for inflammatory skin diseases - CP and FXF. To induce skin inflammation, the NHEK and NHDF 
cell lines were incubated with histamine or LPS and the changes in gene and protein expression, as well as proliferation, epithelial barrier function and wound healing ability were studied.

The hypotheses examined in this study are:

(i) the compounds tested in this study (histamine, LPS, OST, FXF, CP) have no cytotoxic effect on NHEK and NHDF cell lines,

(ii) histamine or LPS induce changes in pro-inflammatory CKs (IL-1 $\beta$, IL-6, tumor necrosis factor-alpha - TNF- $\alpha$ ) and ChKs (IL-8, chemokine (C-C motif) ligand 5/ Regulated on Activation, Normal T-cell Expressed and Secreted CCL5/RANTES and chemokine (C-C motif) ligand 2/ Monocyte Chemoattractant Protein-1 - CCL2/MCP-1) and expression of the genes encoding Toll-Like Receptor 2 (TLR2), cyclooxygenase-2 (COX-2) and nuclear factor kappa $\mathrm{B}(N F-\kappa B)$ in NHEK and NHDF cells,

(iii) OST successively reduces histamine- or LPS-induced inflammation and its corresponding effects,

(iv) OST does not affect the integrity of tight junctions in the keratinocyte monolayer and prevents histamine- or LPSinduced disruption of tight junctions,

(v) OST improves the wound healing process that occurs in persistent inflammation of skin diseases.

\section{Materials and Methods}

\section{Chemicals}

Histamine (CAS 51-45-6), LPS from Escherichia coli O111:B4 (EC 297-473-0), FXF (CAS 153439-40-8), OST (CAS 484-12-8) and CP (CAS 25122-46-7) were obtained from Sigma Aldrich (St. Louis, MO, USA, cat. no. Y0001779, L4391, Y0000789, Y0001207 and Y0000559, respectively). Histamine $(1 \mathrm{mg} / \mathrm{mL})$ and LPS $(0.8 \mathrm{mg} / \mathrm{mL})$ were dissolved in water, FXF $(5 \mathrm{mg} / \mathrm{mL})$, and CP $(25 \mathrm{mg} / \mathrm{mL})$ in DMSO (Sigma Aldrich, St. Louis, MO, USA, cat. no. D8418), while OST $(10 \mathrm{mg} / \mathrm{mL})$ was dissolved in 96\% ethanol (Chempur, Piekary Śląskie, Poland, cat. no. 653964200). The solutions were filtered through $0.22 \mu \mathrm{m}$ pore filters, aliquoted and stored at $-20^{\circ} \mathrm{C}$.

\section{Cell Culture}

The NHEK cell line was purchased from PromoCell GmbH (Heidelberg, Germany, cat. no. C-12005) and cultured in T-75 flasks in keratinocyte medium (Keratinocyte Growth Medium 2 ready to use, PromoCell, Heidelberg, Germany, cat. no. C-20011) prepared according to the manufacturer's instructions. NHEKs were incubated at $37^{\circ} \mathrm{C}$ in a $95 \%$ humidified atmosphere and $5 \% \mathrm{CO}_{2}$. The culture medium was changed every 2-3 days, and cells were passaged when confluence reached approximately $80 \%$. Only early passages (3-7) were used in this study.

The NHDF cell line (PromoCell GmbH, Heidelberg, Germany, cat. no. C-12300) was cultured in a T-75 flask in the recommended culture medium (PromoCell GmbH, Heidelberg, Germany, cat. no. C-23010) containing 1\% of penicillin/ streptomycin solution (Sigma Aldrich, St. Louis, MO, USA, cat. no. P4333). Cells were incubated at $37^{\circ} \mathrm{C}$ in a $95 \%$ humidified atmosphere and 5\% CO2. The culture medium was changed every 2-3 days, and cells were passaged when confluence reached approximately $80 \%$.

\section{Analysis of Cell Proliferation}

The proliferation of NHEK and NHDF cells in the presence of various concentrations of the tested substances was analyzed using the Cell Proliferation ELISA, BrdU (colorimetric) kit (Roche Diagnostics, Basel, Switzerland, cat. no. 11647229001). Cells were seeded in culture medium in 96 -well plates at a concentration of $5 \times 10^{3}$ cells per well. After $24 \mathrm{~h}$, medium was removed and replaced with solutions of the tested substances $(0.1-100 \mu \mathrm{g} / \mathrm{mL}$ histamine, $0.05-2$ $\mu \mathrm{g} / \mathrm{mL}$ LPS, $0.0625-0.5 \mathrm{mg} / \mathrm{mL}$ FXF, OST or CP; alone and in the mixtures) and bromodeoxyuridine (BrdU) in a final volume of $100 \mu \mathrm{L}$. Cells were incubated for 3, 6, 12, 24, 48, and $72 \mathrm{~h}$. After incubation, the medium was removed by flicking off and the cells were dried at $60^{\circ} \mathrm{C}$ for $1 \mathrm{~h}$. The plates were coated with parafilm and stored at $4{ }^{\circ} \mathrm{C}$ for up to 3 days. Then the procedure was performed according to the manufacturer's instructions. The percentage of cells was calculated in comparison to the control (100\%, cells seeded in the recommended medium). 


\section{Migration Analysis}

NHEKs and NHDFs $\left(5 \times 10^{3}\right.$ per well) were seeded in each well of the Culture-Insert 4 well located in the center of a $35 \mathrm{~mm}$ culture dish (Ibidi, Martinsried, Germany, cat no. 80466). After $24 \mathrm{~h}$, the culture insert was removed with sterile tweezers, the cells were washed with 1xPBS to remove non-adherent cells, and fresh media containing the tested substances were added to the culture dish. Images of the wound were taken after at 1, 2, 3, 6, 9, 12, 24, and $48 \mathrm{~h}$ and analyzed using ImageJ software. The results were presented as percentage of wound coverage.

\section{Assessment of Cell Barrier Function}

To investigate the barrier function of cultured NHEK and NHDF cells before and after incubation with the tested compound, $1 \times 10^{5}$ cells per well were seeded in 12 -well cell culture plates in inserts with a pore size of $0.4 \mu \mathrm{m}$ and surface area of $1.13 \mathrm{~cm}^{2}$ (Merck St. Louis, MO, USA, cat. no. MCHT12H48). When the cells reached confluence, the medium for keratinocytes (Lifeline Cell Tech LLC) with low calcium concentration $(0.06 \mathrm{mM})$ was replaced with the medium with high calcium concentration $(1.8 \mathrm{mM})$ to induce keratinocyte differentiation and tight junction maturation. The medium for NHEK and NHDF was changed every second day for 10 days until the cells were fully differentiated and the monolayer reached an appropriate transepithelial electrical resistance (TEER) value (at least $250 \Omega \times \mathrm{cm}^{2}$ ). The inserts containing the confluent differentiated keratinocytes and fibroblasts were then transferred to new 12-well plates, and the medium containing the tested substances was added $(1 \mathrm{~mL}$ of medium into the insert and $2 \mathrm{~mL}$ of medium into the well outside the insert). TEER was measured at 7 time points $(1,3,6,12,24,48$, and $72 \mathrm{~h})$ using a Millicell ERS-2 volt-ohm meter (Merck St. Louis, MO, USA, cat. no. MERS00002, according to the manufacturer's instructions. The TEER value was calculated according to the formula described by Srinivasan et al. ${ }^{34}$ TEER values at different time points were expressed as a percentage of the TEER value at time $0(100 \%)$.

\section{Incubation of NHEK and NHDF Cells with the Investigated Compounds for Analysis of Gene and Protein Expression}

Cells were seeded in culture medium in 24 well-plates at a concentration of $2.5 \times 10^{4}$ cells per well. ${ }^{35,36}$ After $24 \mathrm{~h}$, the medium was removed and replaced with fresh medium with the tested compounds in a volume of $1 \mathrm{~mL}$. The cells were cultured for 12, 24, 48, and $72 \mathrm{~h}$. Thereafter, the medium was collected and total RNA was isolated and reverse transcribed.

\section{RNA Isolation and Reverse Transcription}

Total cellular RNA was extracted using TRIzol Reagent (Invitrogen, Thermo Fisher Scientific, Waltham, MA, USA, cat. no. 15596026) according to the manufacturer's instructions and the protocol described by Kordulewska et al. ${ }^{13}$ RNA concentration and purity $\left(\mathrm{A}^{260} / \mathrm{A}^{280}\right)$ were determined using NanoDrop ND-1000 spectrophotometer (NanoDrop Tech., Inc. Wilmington, DE, USA). Total RNA was reverse transcribed using High-Capacity cDNA Reverse Transcription Kit (Applied Biosystems, Thermo Fisher Scientific, Waltham, MA, USA, cat. no. 4368814) according to the manufacturer's instructions in a Master Cycler Gradient Thermocycler (Eppendorf, Hamburg, Germany).

\section{Quantitative Real-Time PCR (qPCR) and Data Analysis}

The changes in the expression of $T L R 2, N F-\kappa B$ and $C O X-2$ were investigated. Tyrosine 3-Monooxygenase (YWHAZ) was used as a reference gene to normalize the disproportion in mRNA quantity. The oligonucleotide primers specific for each gene are listed in Table S1. The qPCR was performed in the QuantStudio ${ }^{\text {TM }} 3$ Real-Time PCR System using the FastStart Essential DNA Green Master Kit (Roche Diagnostics, Basel, Switzerland, cat. no. 06402001). For each reaction, $5 \mathrm{ng}$ of cDNA was given and qPCR was performed in triplicates as follows: denaturation at $95^{\circ} \mathrm{C}$ for $10 \mathrm{~min}$, amplification and quantification repeated 45 times $\left(95^{\circ} \mathrm{C}\right.$ for $20 \mathrm{~s}, 60^{\circ} \mathrm{C}$ for $20 \mathrm{~s}$ and $72^{\circ} \mathrm{C}$ for $20 \mathrm{~s}$ with a single fluorescence measurement), melting curve at $60-95^{\circ} \mathrm{C}$ with $0.1^{\circ} \mathrm{C}$ per second heating rate and continuous fluorescence measurement, final cooling to $4^{\circ} \mathrm{C}$. A negative control without cDNA and an inter-run calibrator were included in each assay. Gene expression was analyzed according to Pfaffl. ${ }^{37}$ Results were scaled to the expression level of the control, which was determined as one. 


\section{Analysis of Cytokine and Chemokine Levels}

The levels of IL-1 $\beta,-6,-8$, TNF- $\alpha$, CCL2/MCP-1, and CCL5/RANTES were analyzed using enzyme-linked immunosorbent assay (ELISA) supplied by Diaclone (Besancon Cedex, France; IL-1 $\beta$ - cat. no. 851.610.001, TNF- $\alpha$ - cat. no. 851.570.001), Mabtech (Nacka Strand, Sweden; IL-6 - cat. no. 3460-1H-20), BD Biosciences (San Jose, CA, USA; IL-8 - cat. no. 555244) and Abcam (Cambridge, UK; CCL5/RANTES - ab100633, CCL2/MCP-1 - ab179886) according to the manufacturer's protocol. Samples were tested in quadruples. Results were standardized by comparison with a standard curve.

\section{Statistical Analysis}

Data analysis and visualization was performed using GraphPad Prism software version 9 (GraphPad Software, San Diego, CA, USA) and presented as mean \pm standard deviation. Ordinary two-way ANOVA with Tukey's and Dunnett's multiple comparisons tests were used to examine differences between quantitative values. The statistical significance level was set at a $p$-value $<0.05$.

\section{Results}

\section{Osthole Prevents Histamine- or LPS-Induced Cell Proliferation}

The proliferation of NHEK and NHDF cell lines was analyzed after treatment with the investigated compounds to avoid excessive cell mortality during the main experiments. Cell proliferation was analyzed at 6-time points, and it was assumed that the maximum inhibition of proliferation in both cell lines could reach a maximum of $50 \%$ of control. Histamine did not increase proliferation in the NHEK cell line (Figure S1A), but this effect was observed in the NHDF cell line from $12 \mathrm{~h}$ of experiment (igure S1B). In contrast, LPS increased proliferation in both cell lines (Figure S1C, D). Considering the mixtures of histamine or LPS with FXF, CP, and OST, all inflammation inhibitors decreased proliferation, but significance was observed in different time points in the tested variants (Figure S1). FXF, CP, and OST alone also inhibited cell proliferation at all tested concentrations (igure S2). Maximum inhibition of proliferation was observed when $0.5 \mathrm{mg} / \mathrm{mL}$ of $\mathrm{CP}$ was applied for $72 \mathrm{~h}(63.3 \%$ in NHEK, $71.6 \%$ in NHDF; $p<0.0001$ for both; Figure S2E, F). Since this CP concentration is used in the drugs for the treatment of psoriasis, eczema and other skin disorders, ${ }^{38,39}$ we decided to compare the analyzed compounds in furthered experiments at o concentration of $0.5 \mathrm{mg} / \mathrm{mL}$.

\section{Osthole Improves Migration of Keratinocytes and Fibroblasts}

The migration of cells after treatment with OST was evaluated using a wound healing assay, which based on the ability of cells to migrate through a gap created by the insert. OST at all tested concentrations significantly accelerated the migration of NHEKs and NHDFs from 9 and $12 \mathrm{~h}$ of experiment, respectively (Figure 1A and B). Indeed, in NHDF cell line migration was initially slowed (from 3 to $9 \mathrm{~h}$ of experiment) compared to the control (Figure 1B).

\section{Osthole Prevents Histamine- and LPS-Induced Disruption of Tight Junction in NHEK and NHDF Cell Lines Monolayer}

The tight junction integrity of NHEK and NHDF cell lines monolayer was determined by TEER measurement to evaluate the effect of OST on barrier function. In keratinocytes both histamine and LPS improved cell barrier integrity at the beginning of the experiment to reach the level of control after 6 and 12-24 h, respectively (Figure 2A and C). At the next measurement points, the TEER values were significantly lower compared to the control. In fibroblasts, a significant decrease in TEER value was observed after $24 \mathrm{~h}$ (Figure 2B and D). OST, like the reference compounds, significantly improved the integrity of NHEK and NHDF cell lines monolayers treated with histamine and LPS (Figure 2), indicating its anti-inflammatory properties. This effect appears to be directly related to the concentration of OST, as the TEER value increases in a concentration-dependent manner when cells were treated with OST alone (Figure S3C, D). 

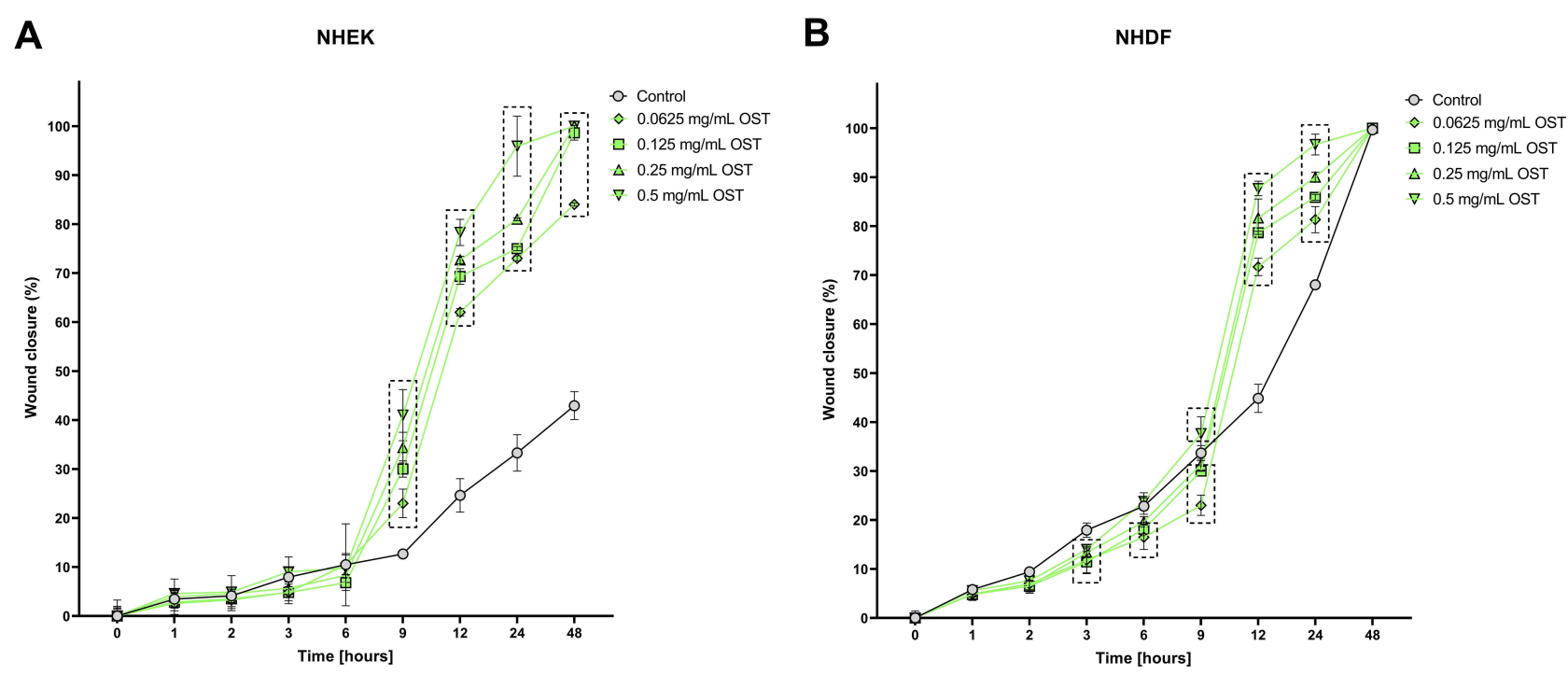

Figure I Changes in migration of Normal Human Epithelial Keratinocytes (NHEK; (A) and Normal Human Dermal Fibroblasts (NHDF; (B) after incubation with osthole (OST). Symbols show the mean and bars show the standard deviation. Statistically significant differences $(p<0.05$, two-way ANOVA with Dunnett's multiple comparisons test) are shown in rectangles with dotted edges.

\section{Osthole Decreases the Secretion of Proinflammatory Cytokines and Chemokines in Histamine- or LPS-Treated NHEK and NHDF Cell Lines}

The changes in the secretion of selected CKs (IL-1 $\beta$, IL-6, and TNF- $\alpha$ ) and ChKs (IL-8, CCL5/RANTES, and CCL2/ MCP-1) in NHEK and NHDF cell lines were examined after incubation with histamine and LPS. Inflammatory mediators significantly increased IL- $1 \beta$ levels in both cell lines at each time point, while OST significantly decreased IL-1 $\beta$ secretion (Figures 3A, B and 4A, B). For the most part, there was no statistically significant difference in IL-1 $\beta$ levels between cells treated with histamine/OST and histamine/CP. It is worth to notice that in the NHDF line no IL$1 \beta$ secretion was observed in the control group (Figure 4A and B). Importantly, OST not only prevented IL-1 $\beta$ secretion under inflammatory conditions (histamine/OST treatment), but also decreased secretion in the NHEK cell line alone in a concentration-dependent manner (Figure S4B). IL-1 $\beta$ secretion was not observed in the FXF-, OST-, and CP-treated NHDF cell line (data not shown). A different trend was observed in the secretion of IL-6, as it was higher or similar when cell lines were treated with a mixture of histamine/LPS and an anti-inflammatory drugs compared to histamine/LPS alone (Figures 3C, D and 4C, D). In addition, LPS has been found to increase secretion of IL-6 twofold compared to histamine (Figures 3C, D and 4C, D). No statistically significant difference was found between the IL-6 levels in cell lines treated with OST and CP (Figures 3C, D and 4C, D), but the IL-6 level was slightly decreased when cells were treated with OST alone (Figure S4E, S5B). The highest IL-8 levels were measured in NHEK and NHDF cell lines stimulated with histamine/LPS and FXF, while mixtures with OST and CP increased IL-8 secretion compared with histamine/LPS alone, but the IL-8 levels in these two groups were comparable (Figures 3C, D and 4C, D). Again, no statistically significant difference in IL-8 secretion was found between the cells supplemented with the mixture of histamine/LPS and CP or OST (Figures 3C, D and 4C, D). OST significantly decreased IL-8 secretion, but a concentration-dependent manner was observed only in the NHEK cell line (Figure

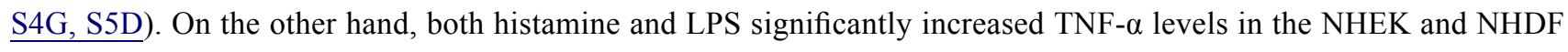
cell lines, while FXF, and especially OST and CP attenuated this effect (Figures 3G, H and 4G, H). There was no statistically significant difference in TNF- $\alpha$ levels in cells treated with histamine/LPS and CP or OST (Figures 3G, $\mathrm{H}$ and $4 \mathrm{G}, \mathrm{H}$ ). TNF- $\alpha$ was not secreted, when cells were treated with FXF, OST, and CP alone (data not shown). OST significantly reduces the secretion of CCL2/MCP-1 and CCL5/RANTES (Figure 5) caused by histamine or LPS treatment. Importantly, no statistical significance was found between the OST and CP groups. 
A

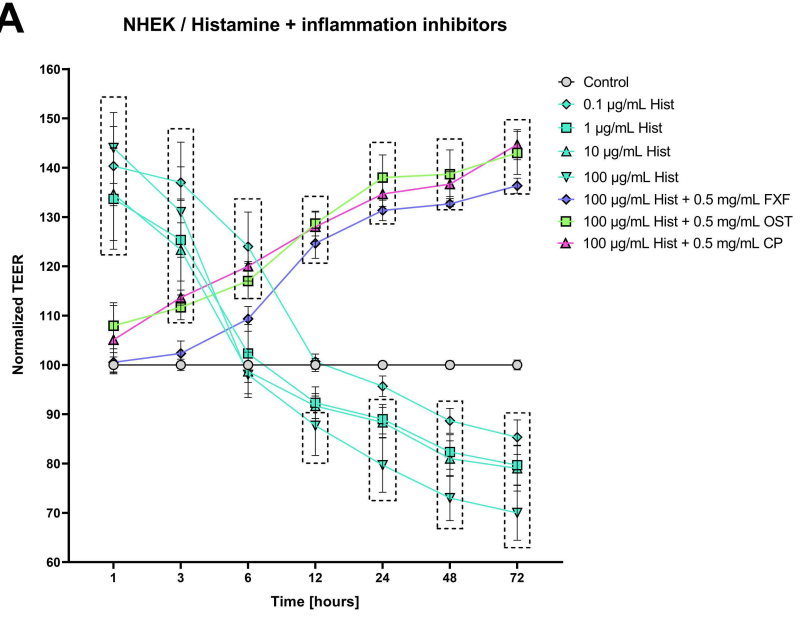

C

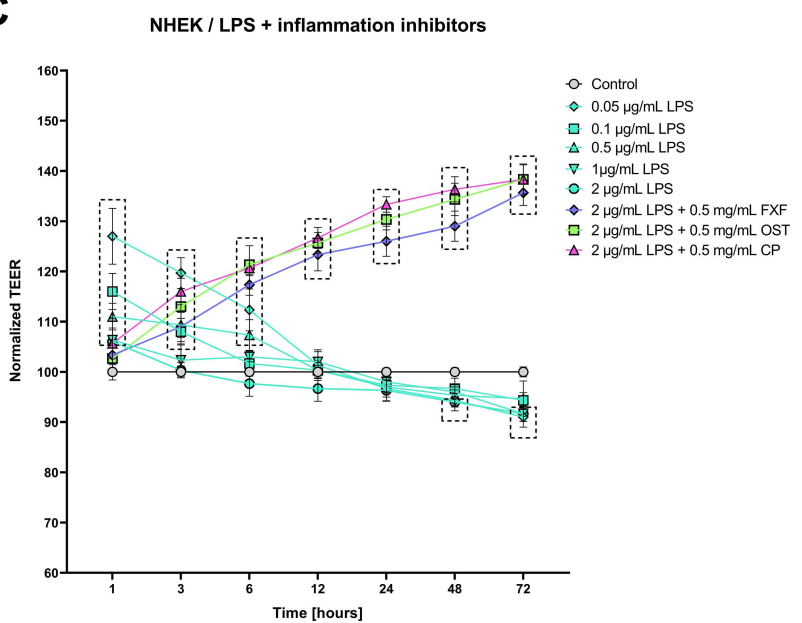

B

NHDF / Histamine + inflammation inhibitors

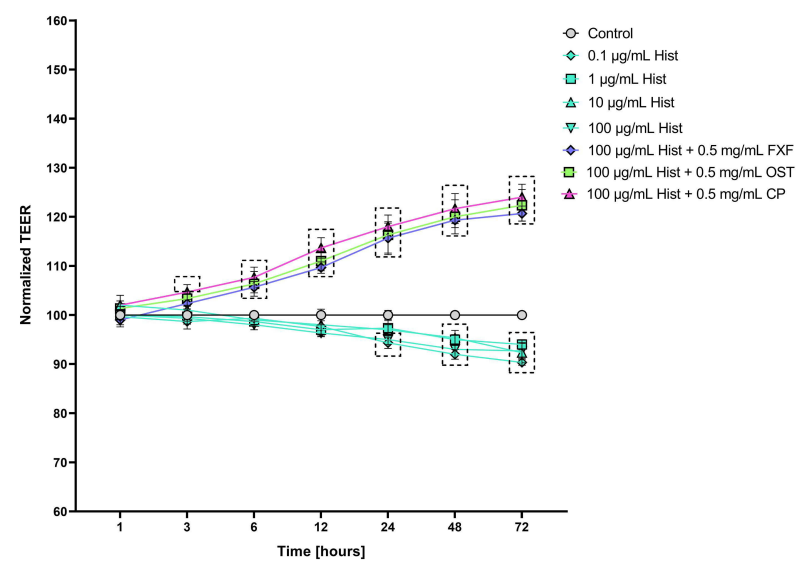

D

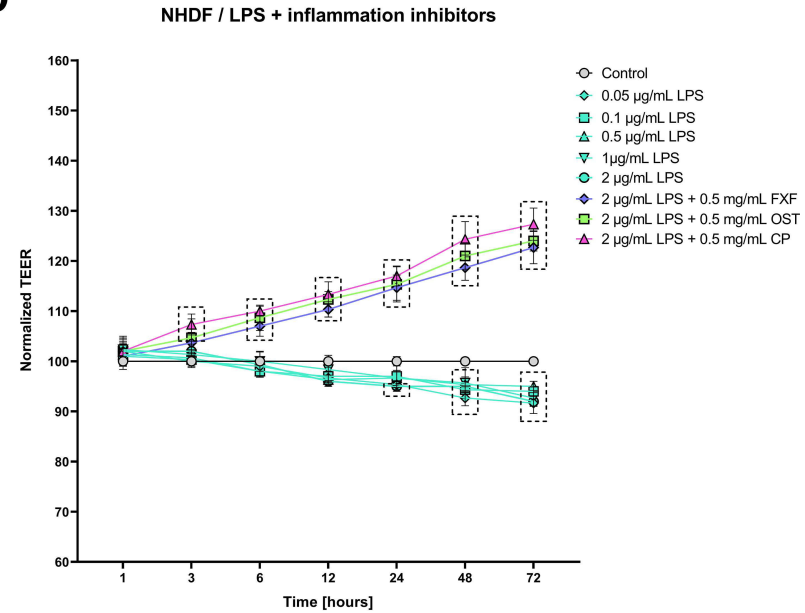

Figure 2 Changes in the integrity of Normal Human Epithelial Keratinocytes (NHEK) and Normal Human Dermal Fibroblasts (NHDF) monolayers after incubation with histamine (Hist; (A and B)) or lipopolysaccharide (LPS; (C and D)) alone or in mixtures with fexofenadine (FXF), osthole (OST), and clobetasol propionate (CP), indicated by measurement of transepithelial electrical resistance (TEER). Symbols indicate the mean and bars indicate the standard deviation. Statistically significant differences $(p<$ 0.05, two-way ANOVA with Dunnett's multiple comparisons test) are shown in rectangles with dotted edges.

\section{Osthole Downregulates TLR2, NF- $\mathrm{kB}$, and COX-2 Expression in Histamine/LPS- Induced NHEK and NHDF Cell Lines}

Overexpression of Toll-like Receptors (TLRs) has been reported to mark an active inflammatory response and trigger downstream NF- $\mathrm{KB}$ signaling. ${ }^{40} \mathrm{NF}-\mathrm{\kappa B}$ is a crucial regulatory transcription factor involved in major inflammatory pathways and regulates the expression of many inflammatory genes, including $I L-6$, and the production of CKs. ${ }^{41} \mathrm{NF}-$ $\kappa \mathrm{B}$ exists in the cytoplasm in an inactive form, bound to the NF- $\kappa \mathrm{B}$ inhibitor alpha ( $\mathrm{I} \kappa \mathrm{B} \alpha$ ). Upon stimulation, the NF- $\mathrm{KB}$ subunit separates from I $\mathrm{B} \alpha$ and migrates to the nucleus, where it triggers the transcription of several inflammatory genes. ${ }^{42}$ Therefore the effect of OST on TLR2, NF- $\kappa B$, and COX-2 expression were investigated in NHEK and NHDF cell lines treated with histamine and LPS. Histamine and LPS significantly increased the expression level of TLR2 (Figures 6A, B and 7A, B). A 10.3- and 13.8-fold increase was observed in the NHEK cell line compared to control (Figures 6A and B), while a 7.1 and 12.4-fold increase was observed in the NHDF cell line after $12 \mathrm{~h}$ of incubation (Figures 7A and B). It should be underlined that the mixtures of LPS and FXF, caused an even greater increase of TLR2 expression in both cell lines than LPS alone (Figures 6A, B and 7A, B). OST significantly decreased TLR2 expression at each of the time points in NHEK and NHDF cells. Importantly, its effect was comparable to that of CP, as no significant difference was observed between cells treated with the mixtures of histamine/LPS and OST or CP (Figures 6A, B and 7A, B). The tested inflammatory inducers also increased the expression level of $N F-\kappa B$, as in the NHEK cell line 12.1- 
A
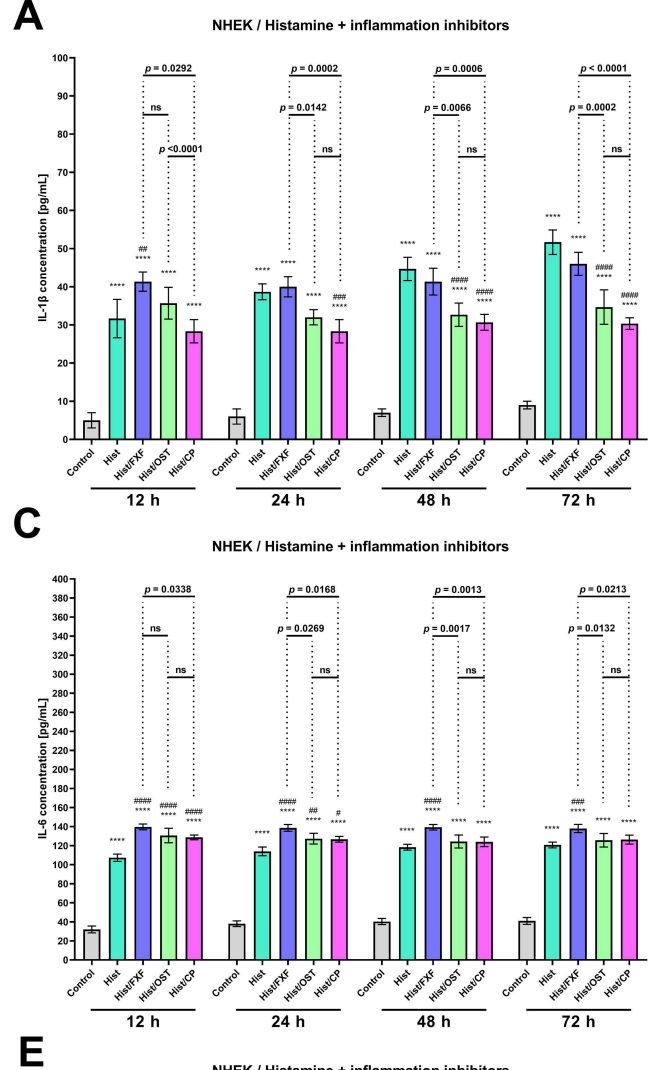

E

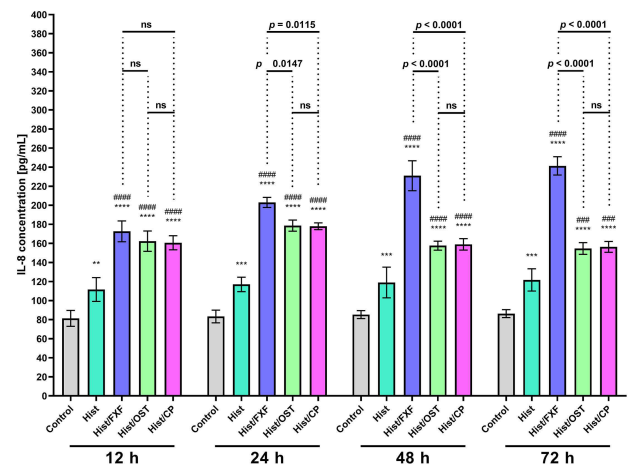

G

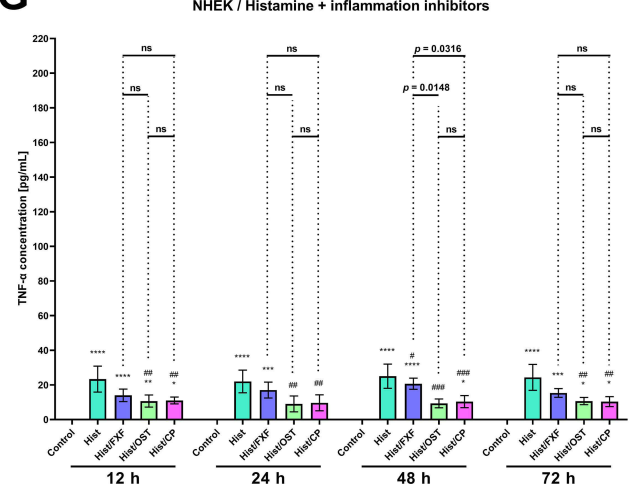

B

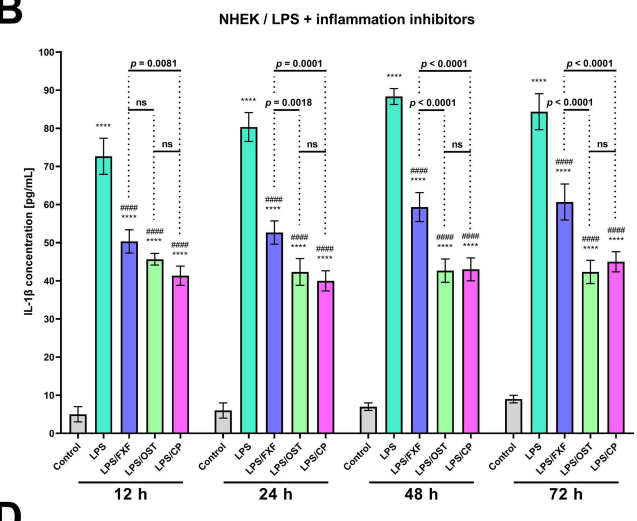

D

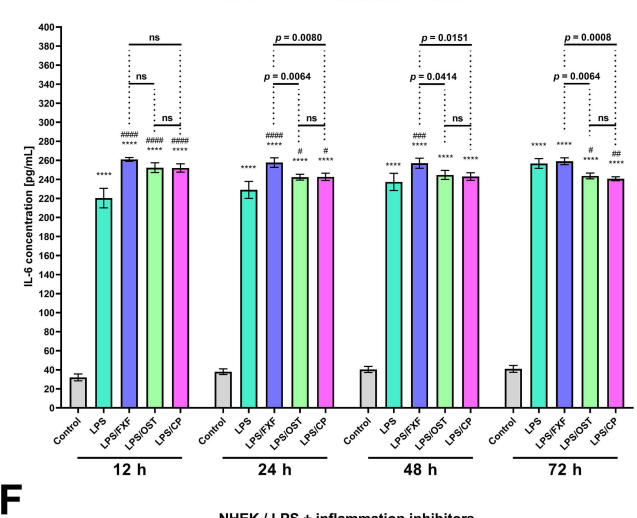

F

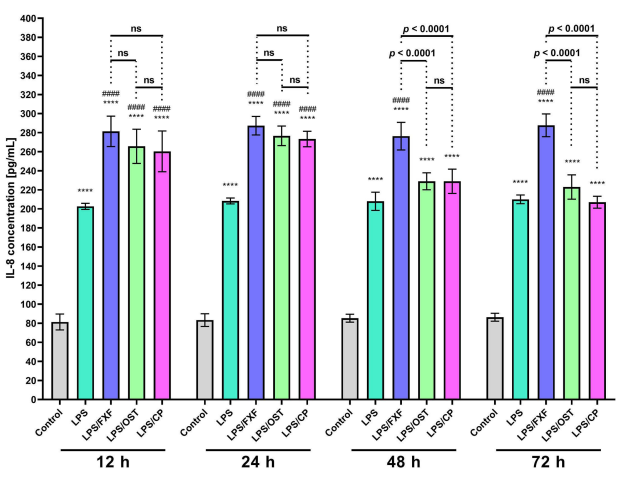

H

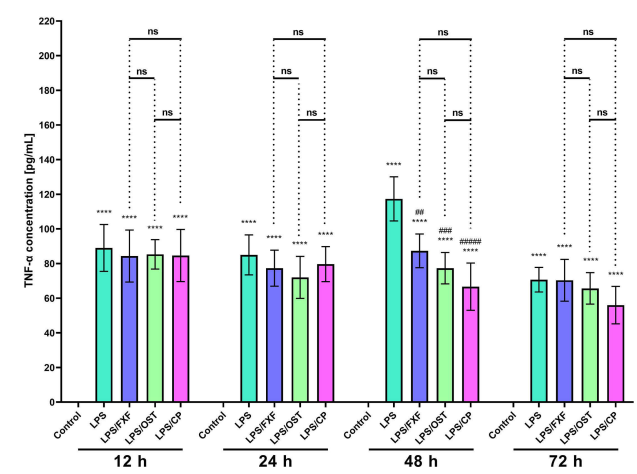

Figure 3 The level of IL -I $\beta$ (A and B), IL-6 (C and D), IL-8 (E and F) and TNF- $\alpha(\mathbf{G}$ and $\mathbf{H})$ after incubation with histamine (Hist; $100 \mu \mathrm{g} / \mathrm{mL})$ ), lipopolysaccharides (LPS; 2 $\mu \mathrm{g} / \mathrm{mL}$ ) alone and in mixtures with fexofenadine (FXF), osthole (OST) and clobetasol propionate (CP; $0.5 \mathrm{mg} / \mathrm{mL}$ ) in Normal Human Epithelial Keratinocytes (NHEK). The horizontal line shows the mean and the bars show the standard deviation. Statistically significant differences (Two-way ANOVA with Tukey's multiple comparisons test)

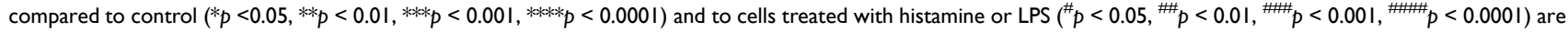
marked; ns - non- significant. 
A

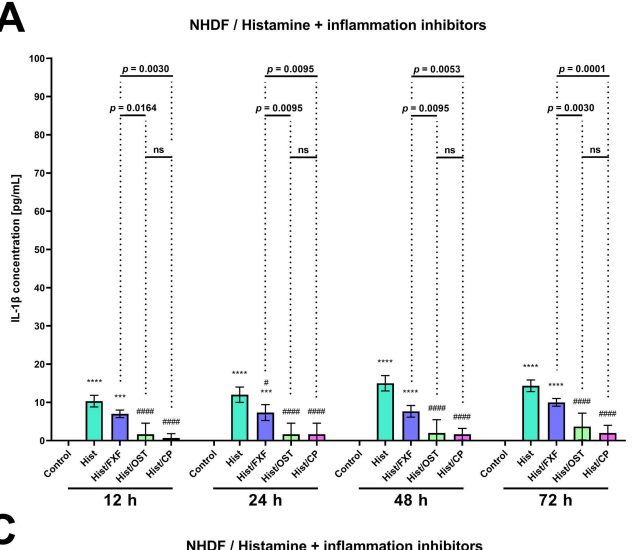

C

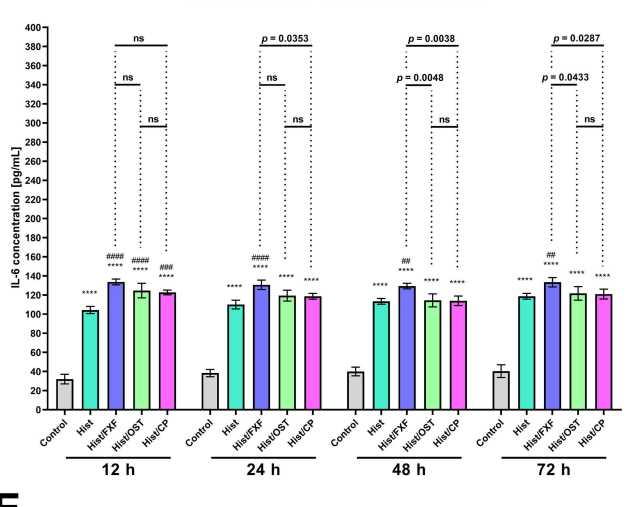

E

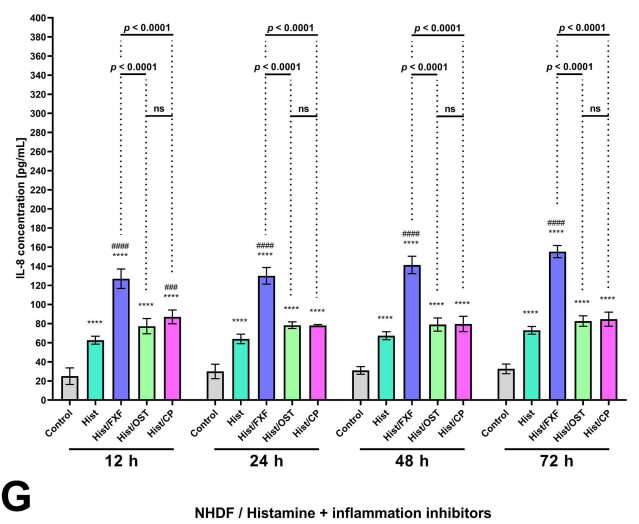

G

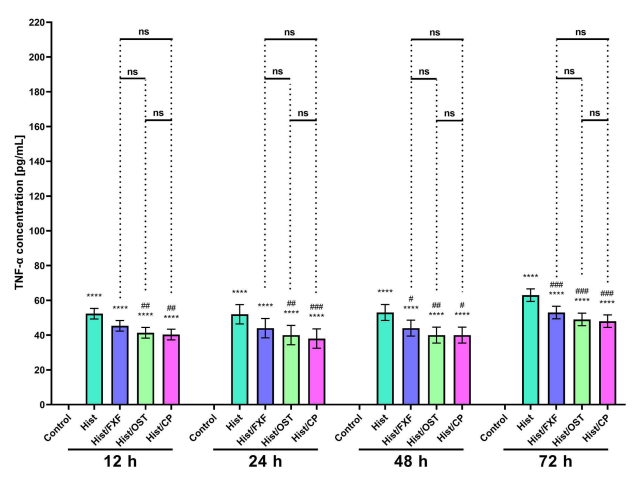

B

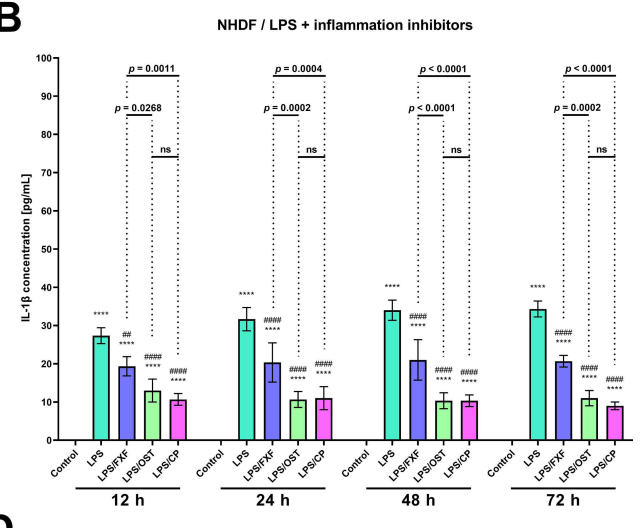

D

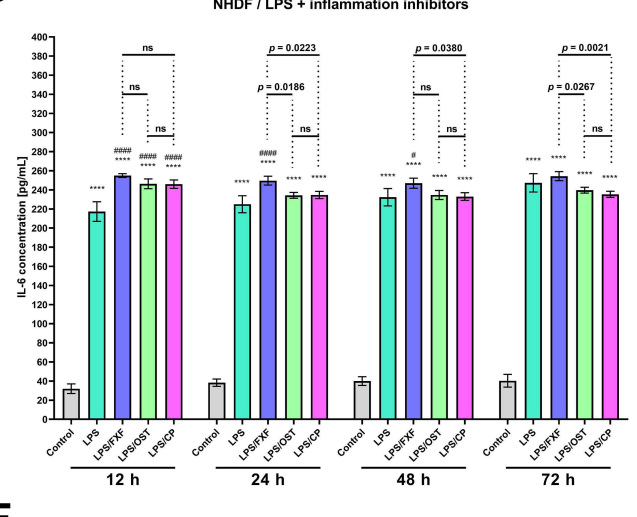

F

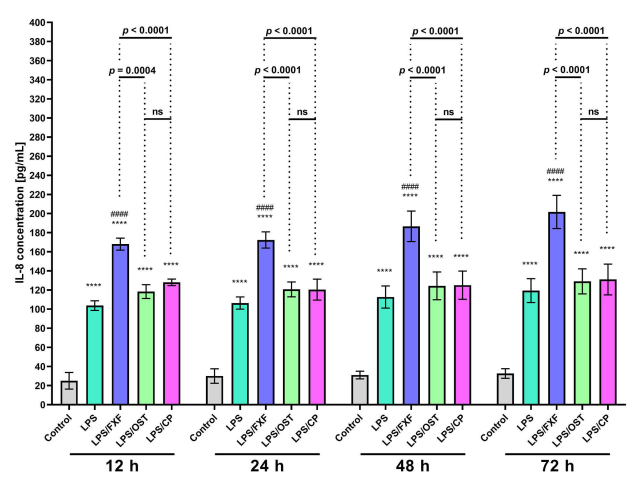

H

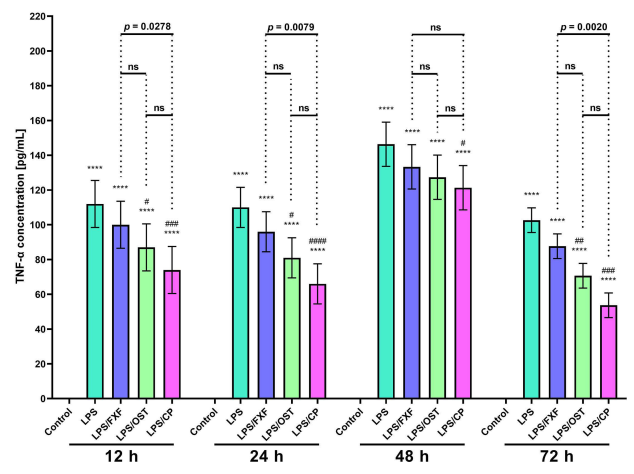

Figure 4 The level of IL-I $\beta$ (A and B), IL -6 (C and D), IL-8 (E and F), and TNF- $\alpha(\mathbf{G}$ and $\mathbf{H})$ after incubation with histamine (Hist; I00 $\mu$ g/mL), lipopolysaccharides (LPS; 2 $\mu \mathrm{g} / \mathrm{mL}$ ) alone and in mixtures with fexofenadine (FXF), osthole (OST) and clobetasol propionate (CP; $0.5 \mathrm{mg} / \mathrm{mL}$ ) in Normal Human Dermal Fibroblasts (NHDF). The horizontal line shows the mean and the bars show the standard deviation. Statistically significant differences (Two-way ANOVA with Tukey's multiple comparisons test) compared to control (****p $<0.000 \mathrm{I})$ and to cells treated with histamine or LPS $\left({ }^{\#} \mathrm{p}<0.05, \#_{\mathrm{p}}<0.0 \mathrm{I}\right.$, \#\# $\mathrm{p}<0.00 \mathrm{I}$, \#\#\# $\left.<0.000 \mathrm{I}\right)$ are marked; ns - non-significant. 
A

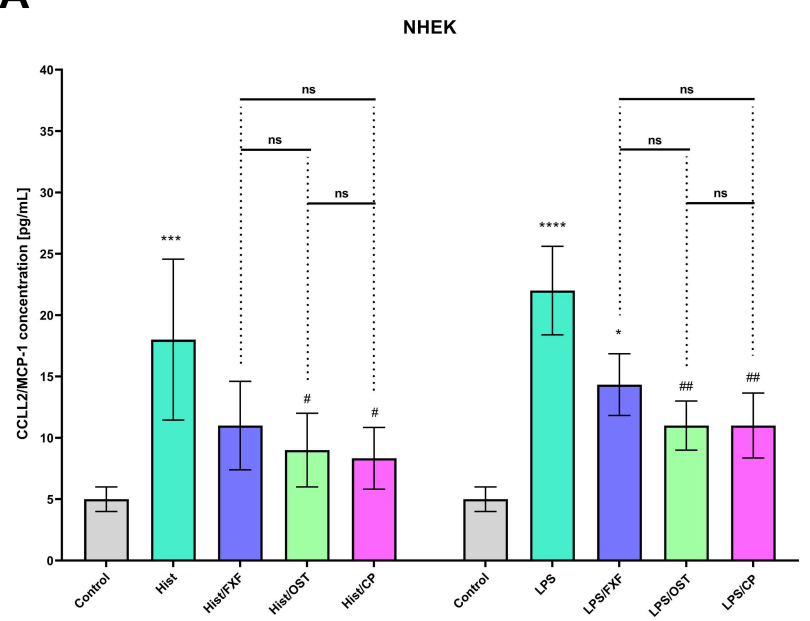

C

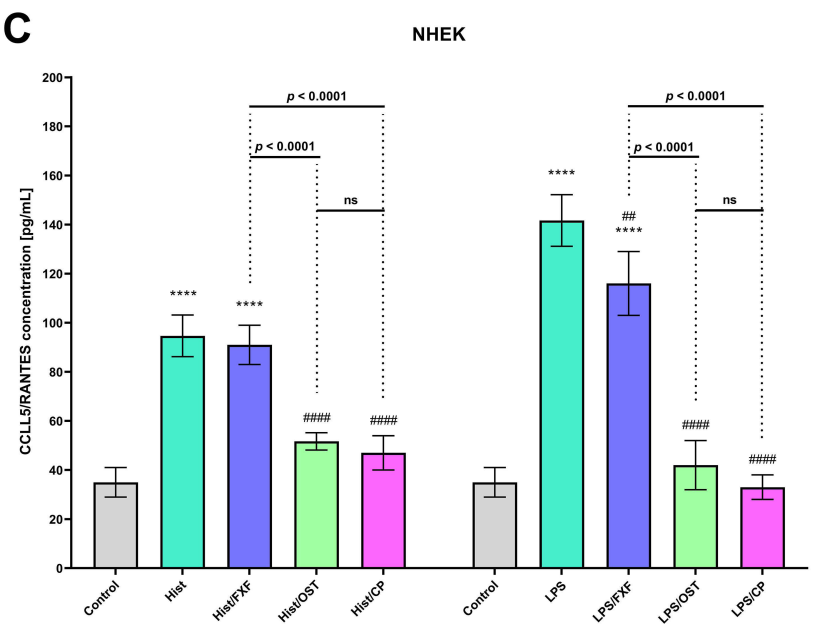

B

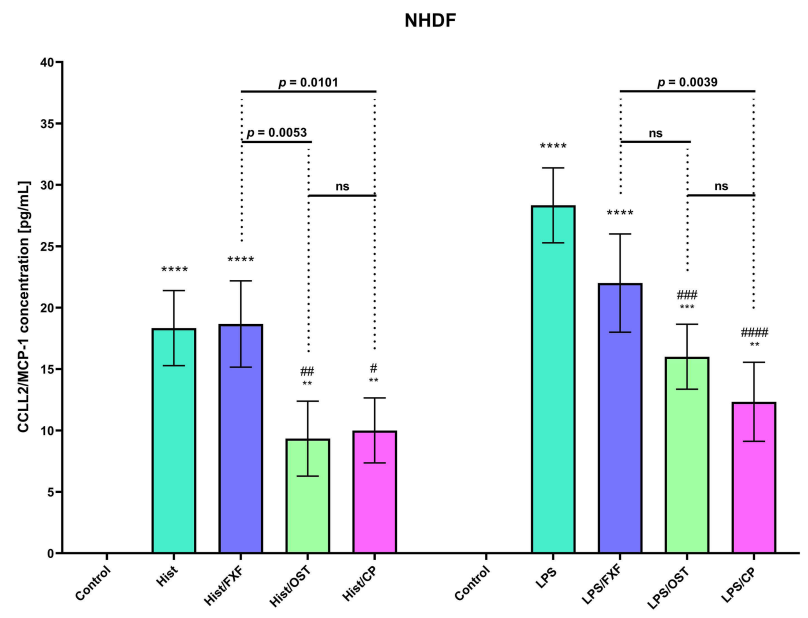

D

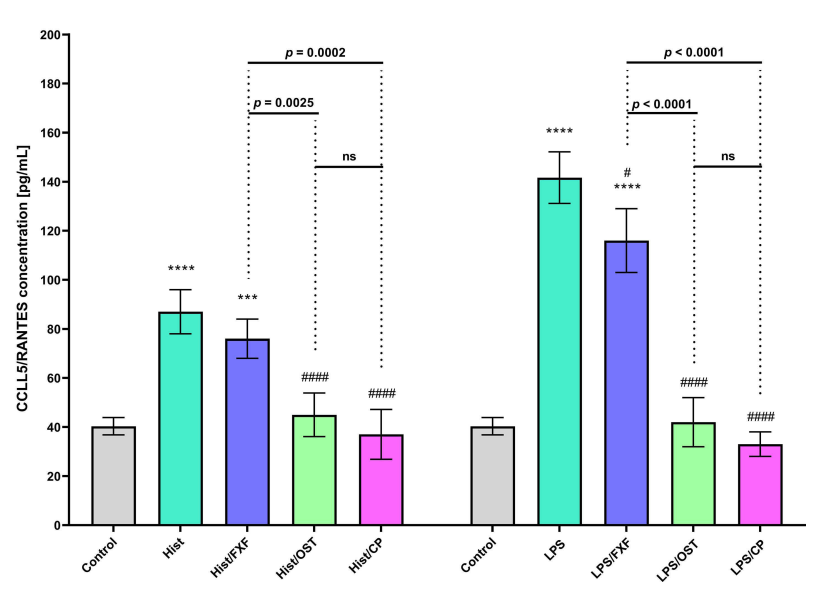

Figure 5 CCL2/MCP-I and CCL5/RANTES levels after incubation with histamine (Hist; $100 \mu g / m L)$, lipopolysaccharides (LPS; $2 \mu g / m L)$ alone and in mixtures with fexofenadine (FXF), osthole (OST) and clobetasol propionate (CP; $0.5 \mathrm{mg} / \mathrm{mL}$ ) in Normal Human Epithelial Keratinocytes (NHEK; (A and C)) and Normal Human Dermal Fibroblasts (NHDF; (B and D)). The horizontal line shows the mean and the bars show the standard deviation. Statistically significant differences (Two-way ANOVA with

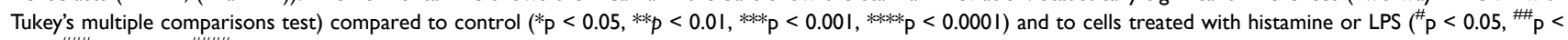
$0.01, \ldots+0.001, \ldots+0.0001$ ) are marked; ns - non-significant.

and 13.2-fold (Figures 6C and D), and in NHDF cells 6.5- and 12.0-fold increases were observed (Figure 7C and D). Again, OST significantly reduced inflammatory mediators-induced $N F-\kappa B$ expression in both cell lines at each time point. A significant difference in $N F-\kappa B$ levels after treatment with histamine/LPS and OST and CP were observed only in the NHEK cell line after 12 and $24 \mathrm{~h}$ of the experiment (Figure 6C and D). Expression of $C O X-2$ increased 9.2- and 7.8-fold in NHEK and 4.9- and 7.7-fold in NHDF treated with histamine (Figure 6E and F) and LPS (Figure 7E and F), respectively. Similar to the previously described results, OST significantly reduced the expression of the COX-2 gene, which increased after stimulation with inflammatory mediators. This time, its effect was comparable to that of $\mathrm{CP}$, as the expression of COX-2 was higher in cells treated with OST, especially in cells stimulated with histamine (Figures 6C, $\mathrm{D}$ and $7 \mathrm{C}, \mathrm{D})$.

\section{Discussion}

The present study provided two new findings: i) OST alleviates skin inflammation in keratinocytes (NHEK) and fibroblasts (NHDF), ii) the inhibitory effect of OST in keratinocytes and fibroblasts might be related to decreased $T L R 2 / N F-\kappa B$ gene expression. A growing number of studies have shown that natural products from traditional medicinal plants are becoming an important source for the discovery of anti-inflammatory drugs. ${ }^{43,44}$ 
A

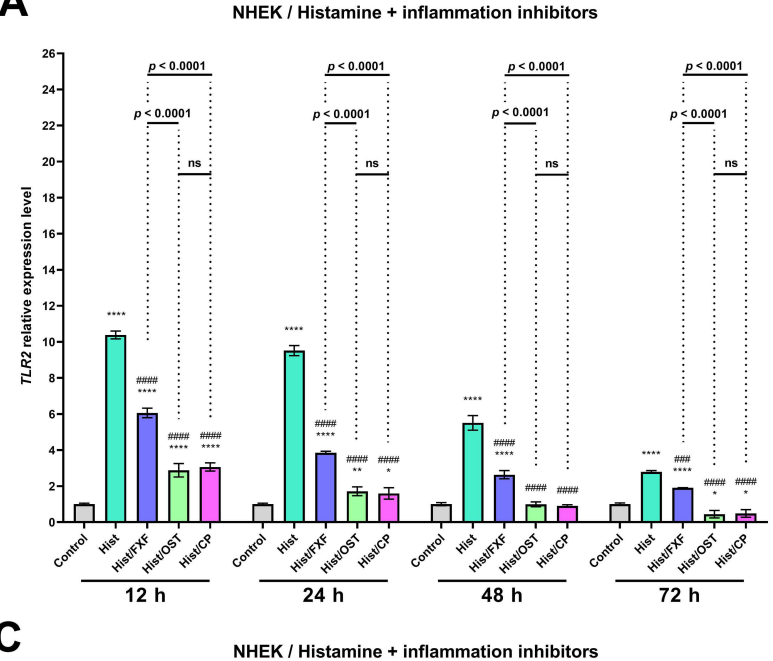

C

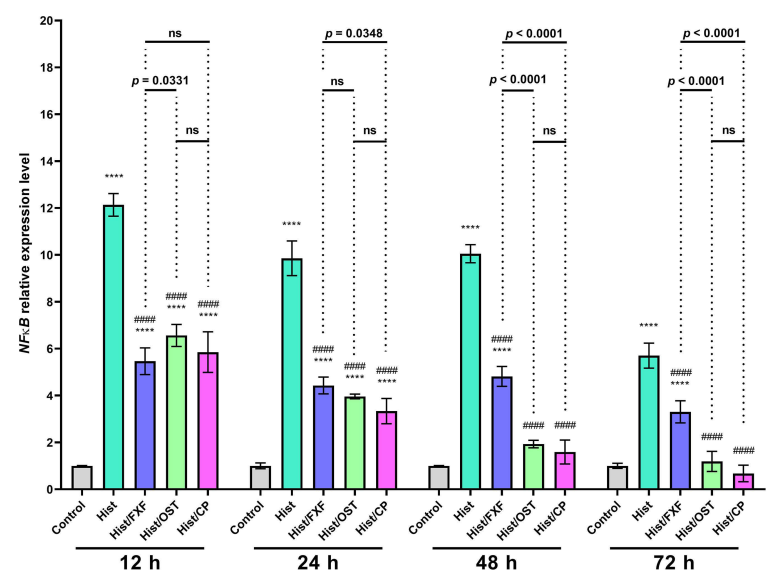

E

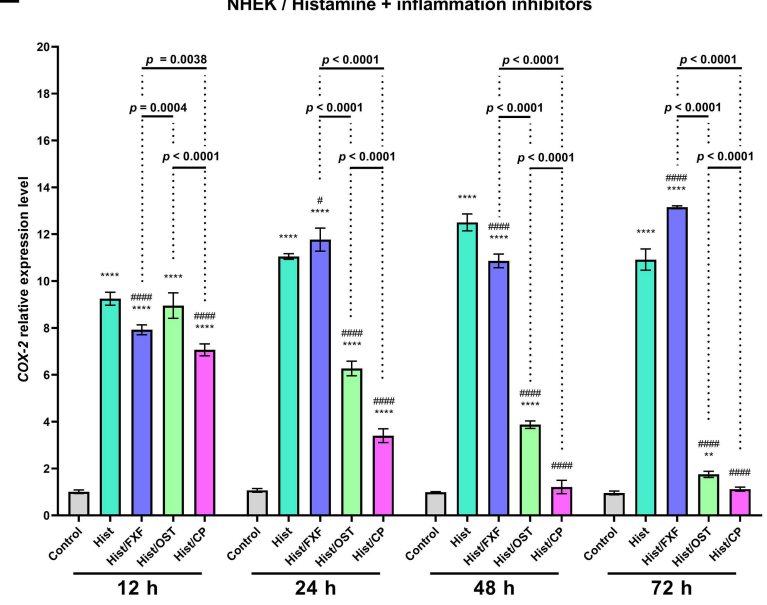

B

NHEK / LPS + inflammation inhibitors

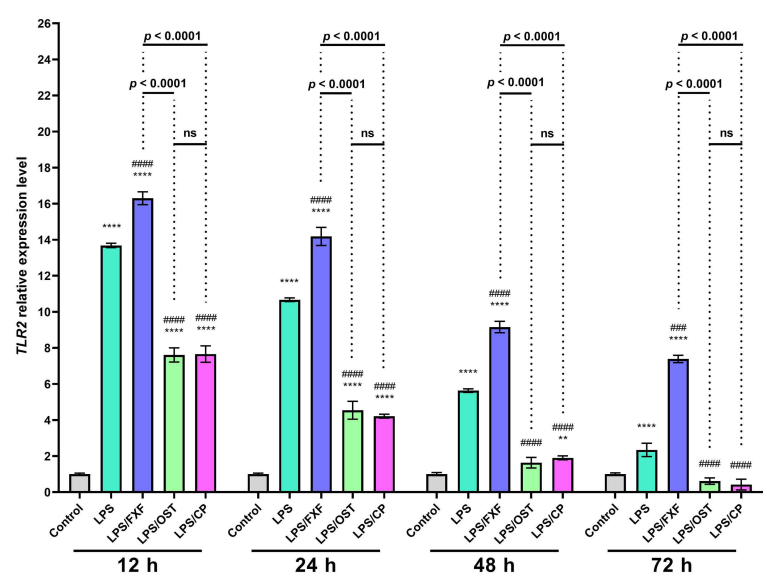

D

NHEK / LPS + inflammation inhibitors

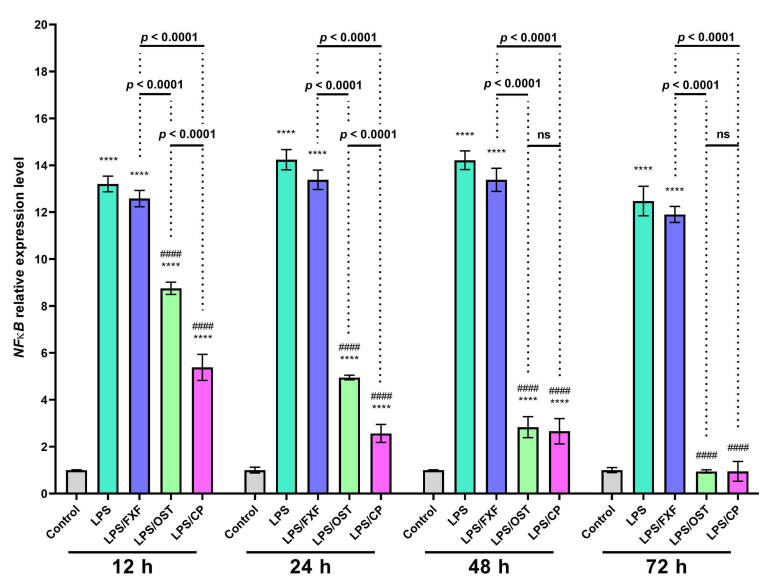

F

NHEK / LPS + inflammation inhibitors

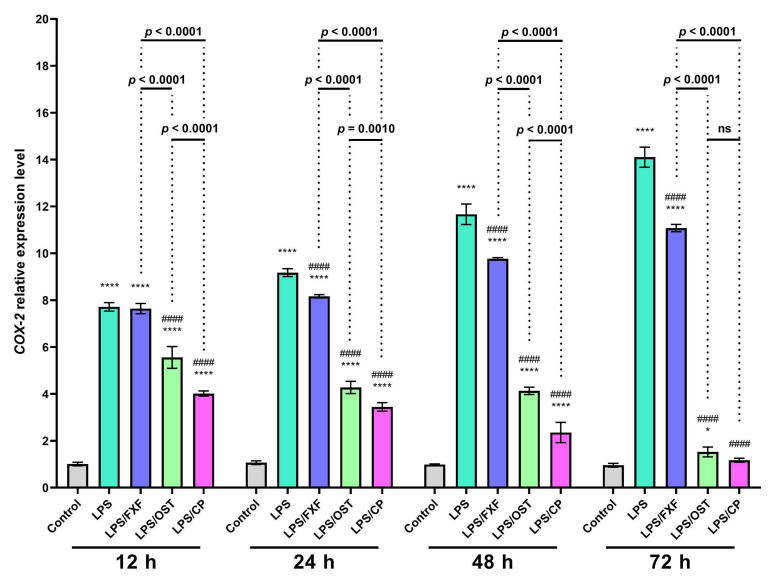

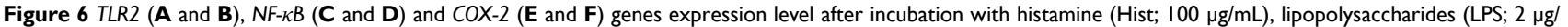
$\mathrm{mL}$ ) alone and in mixtures with fexofenadine (FXF), osthole (OST) and clobetasol propionate (CP; $0.5 \mathrm{mg} / \mathrm{mL}$ ) in Normal Human Epithelial Keratinocytes (NHEK). The horizontal line shows the mean and the bars show the standard deviation. Statistically significant differences (Two-way ANOVA with Tukey's multiple comparisons test)

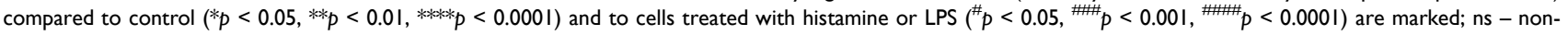
significant. 
A

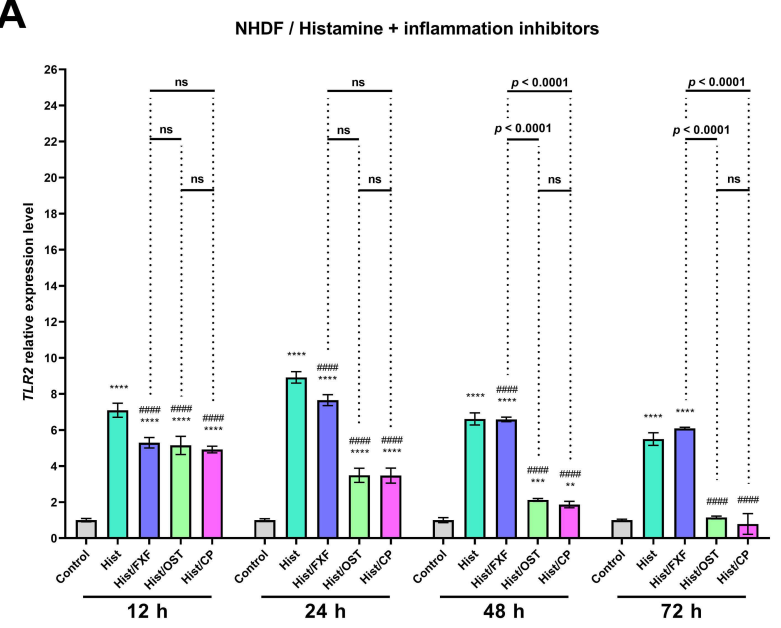

C

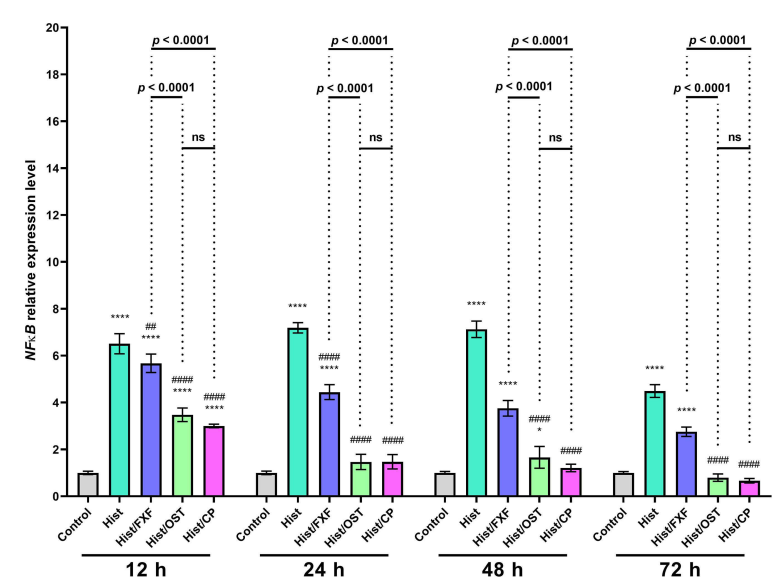

E

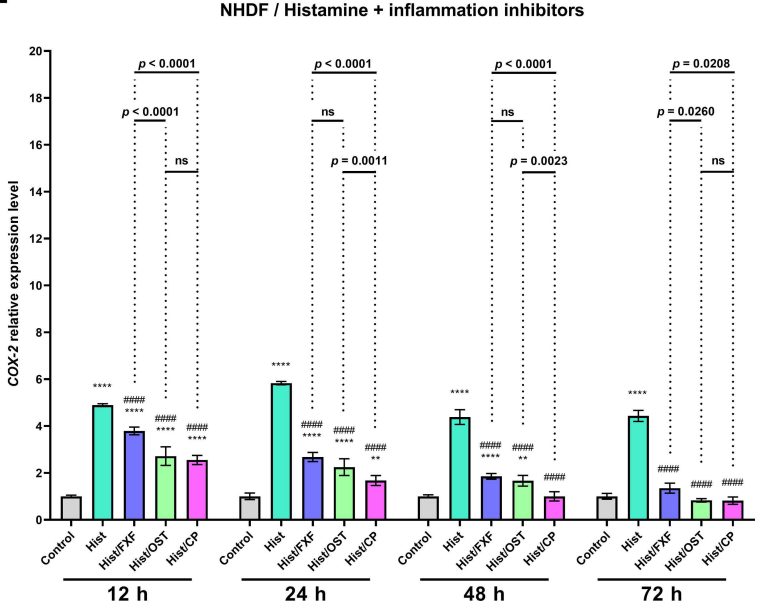

B

NHDF / LPS + inflammation inhibitors

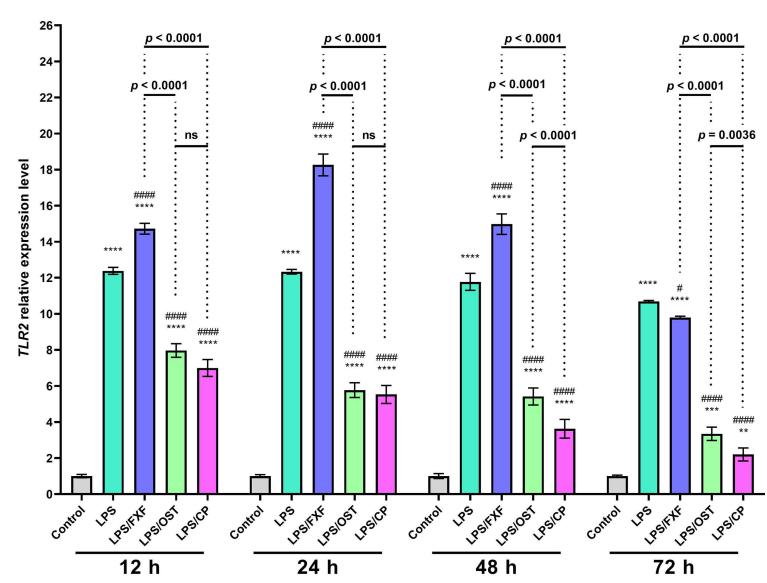

D

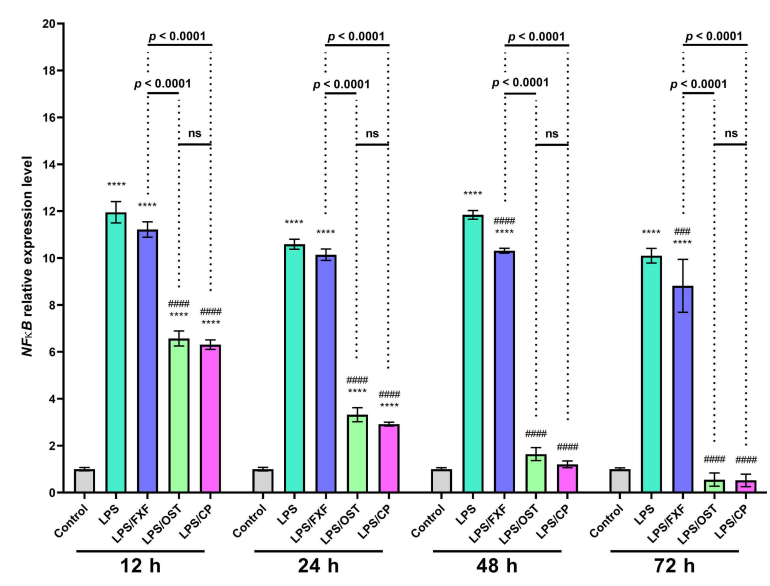

$\mathbf{F}$

NHDF / LPS + inflammation inhibitors

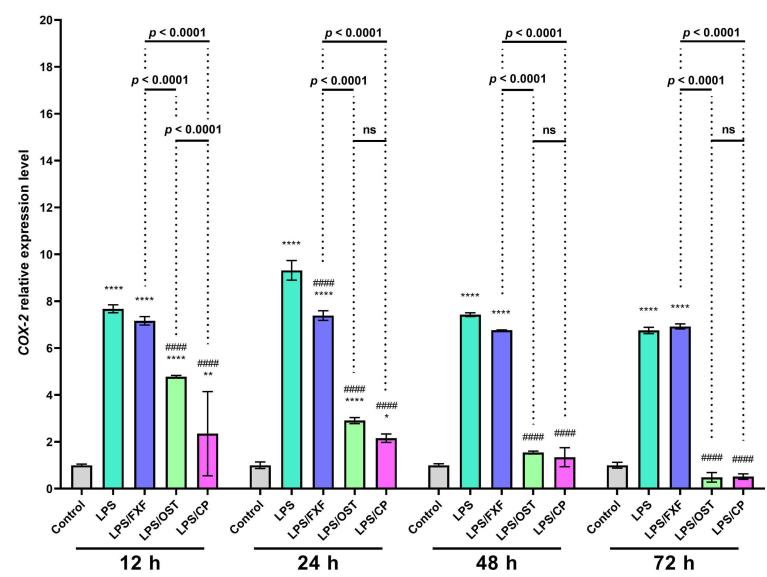

Figure 7 TLR2 (A and B), NF- $\kappa B$ (C and D), and COX-2 (E and F) genes expression level after incubation with histamine (Hist; $100 \mu \mathrm{gg} / \mathrm{mL})$, lipopolysaccharides (LPS; $2 \mu \mathrm{g} /$ $\mathrm{mL}$ ) alone and in mixtures with fexofenadine (FXF), osthole (OST) and clobetasol propionate (CP; $0.5 \mathrm{mg} / \mathrm{mL}$ ) in Normal Human Dermal Fibroblasts (NHDF). The horizontal line shows the mean and the bars show the standard deviation. Statistically significant differences (Two-way ANOVA with Tukey's multiple comparisons test)

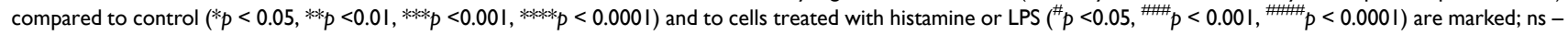
non-significant. 
Overreaction of the skin's immune system due to chronic inflammation can lead to dry skin blemishes and severe itching. ${ }^{45}$ The complex interplay of barrier dysfunction and activation of skin inflammation contributes to the ability of microbes and allergens to penetrate through damaged skin and to the progression of inflammatory skin diseases. ${ }^{46}$ Skin barrier dysfunction results in increased irritability ${ }^{47,48}$ characterized by persistent inflammation leading to uncontrolled proliferation and differentiation of keratinocytes ${ }^{48}$ that produce large amounts of CKs and promote a deviation of type 2 immunity. ${ }^{49,50}$

Currently, $\mathrm{CP}$ is a potent corticosteroid most commonly used in dermatology, mainly for the treatment of inflammatory skin conditions such as psoriasis, AD or skin manifestations of autoimmune diseases. ${ }^{51,52}$ Despite the CP effectiveness, its continued use is associated with many side effects, ${ }^{53}$ therefore it is so important to search for new natural agents with a smaller spectrum of action and a selected target of inhibition of skin inflammation. The herbal medicines have experienced a renaissance in recent years, because they have few side effects compared to chemical drugs. ${ }^{54}$ In our study, one of the reference compounds is $\mathrm{CP}$, which is prescribed as first-line therapy for inflammatory skin diseases. ${ }^{55,56}$ Since histamine and LPS were used to stimulate the inflammatory response in the research model, an antihistamine that has highly selective antagonistic activity at peripheral histamine receptors, FXF, was included as positive control in the study.

Previously, the use of natural products was considered very reliable in the treatment of diseases caused by immune inflammation of the skin. ${ }^{57}$ Based on previous studies, we hypothesized that OST is a promising therapeutic agent for inflammatory skin diseases caused by bacterial infections and by sudden histamine release due to contact allergies.

The literature indicates that OST possesses various biological activities: ${ }^{58}$ anti-inflammatory ${ }^{2,59,60}$ antibacterial, ${ }^{61}$ antiviral, ${ }^{6}$ antifungal, ${ }^{62,63}$ antioxidant, ${ }^{64,65}$ antithrombotic, ${ }^{66}$ antidiabetic, ${ }^{67}$ antispasmodic, ${ }^{68,69}$ and anti-tumor. ${ }^{4,70,71}$ Coumarins are considered as drug candidates with diverse pharmacological activities benefiting from their attractive properties such as low molecular weight, simple structure, high solubility, low side effects, low drug resistance, high bioavailability, broad spectrum of activity, and better curative effect. ${ }^{58,72}$

In the present study, we confirmed that none of the tested compounds at different concentrations caused inhibition of proliferation in the NHEK and NHDF cell lines, allowing us to continue the experiments. Proliferation decreased to 74\% in the NHEK cell line and $89 \%$ in NHDF compared to the control after $24 \mathrm{~h}$ of incubation with the highest concentration $(0.5 \mathrm{mg} / \mathrm{mL}-2 \mathrm{mM})$ of OST (Figure S2C, D) . Our results suggest that the maximum inhibitory concentration (IC50) of OST is higher for NHEK and NHDF than for other cell lines. Chou et al showed that the IC50 of OST for the epithelial HeLa cell line was $64.9 \mu \mathrm{M}$ compared with $168 \mu \mathrm{M}$ for normal cervical fibroblasts. ${ }^{73}$ Moreover, the IC50 for the human leukemia HL-60 cell line was $100 \mu \mathrm{M}$, while it was $164 \mu \mathrm{M}$ for PBMCs. ${ }^{74}$ Accordingly, no significant inhibition of proliferation was observed in PBMCs until $72 \mathrm{~h}$ after treatment with OST at $1.84 \mu \mathrm{M} .{ }^{12}$ Moreover, treatment with 200 $\mu \mathrm{M}$ OST for 24 and $48 \mathrm{~h}$ had no significant cytotoxic effect on normal ovarian IOSE80 cells, whereas ovarian cancer cell lines (A2780, OV2008) were sensitive to treatment with OST at a dose of $200 \mu \mathrm{M}$ for 24 and 48 hours. $^{75}$ In addition, we investigated the influence of histamine and LPS on the proliferation of keratinocytes and fibroblasts, since these mediators are present in increased concentrations in the skin of patients with inflammatory skin diseases. ${ }^{76,77}$ Jensen et al demonstrated that proliferation of keratinocytes was increased 5 -fold in the skin of patients with $\mathrm{AD},{ }^{78}$ while Glatzer et al showed that this effect was mediated by the histamine 4 receptor. ${ }^{79}$ In our study, LPS (Figure S1C), but not histamine (Figure S1A) significantly increased the proliferation of NHEK compared with control, while a significant increase in proliferation was observed in NHDF when cells were treated with both inflammatory mediators (Figure S1B, D). These results are consistent with data from the literature indicating the proliferation-promoting effect of histamine in keratinocytes from $\mathrm{AD}$ patients. ${ }^{78,79}$

Another hypothesis confirmed in our research was that histamine and LPS induce changes in pro-inflammatory CKs and ChKs secretion, and OST successively reduces these effects. TNF- $\alpha$ and other CKs (IL-1 $\beta$, IL-6) involved in the inflammatory response play a central role in numerous acute and chronic inflammatory diseases. ${ }^{80-83}$ Therefore, suppressing the production of inflammatory mediators and inhibiting the secretion of pro-inflammatory CKs may reduce the inflammatory response, ${ }^{84-86}$ which is an important therapeutic target. The current study is the first which investigate the anti-inflammatory effects of OST on histamine/LPS-induced inflammation in NHEK and NHDF cell lines. We demonstrated that IL-1 $\beta$, IL-6, IL-8, TNF- $\alpha$, CCL2/MCP-1 and CCL5/RANTES were significantly increased after 
histamine/LPS stimulation, but their levels decreased after stimulation with OST (Figures 3-5). Therefore, treatment with OST could be a reliable strategy to inhibit the inflammatory mediators in histamine- or LPS-induced inflammation of the skin. These results are consistent with previous studies by $\mathrm{Wu}$, in which the author demonstrated that OST significantly decreased the secretion of IL-1 $\beta$, IL-6, IL-8, and CCL2/MCP-1 in the HepG2 cell line. In addition, OST regulated the expression of genes encoding IL-1 $\beta$, IL-6, IL-8, and CCL2/MCP- $1{ }^{60}$ The presented results are also consistent with those of $\mathrm{Li}$ et al, where the authors showed that OST activated macrophages in ovalbumin-induced asthma in a mouse model, ${ }^{87}$ and significantly decreased the level of IL- $1 \beta$ and TNF- $\alpha$ in bronchoalveolar lavage ${ }^{87}$ and serum. ${ }^{88}$ OST stimulation also downregulated proinflammatory mediators (TNF- $\alpha$, IL-1 $\beta$, COX-2, and iNOS) expressed in the ischemic cortex ${ }^{89}$ and persistent lung inflammation. ${ }^{90}$ These results suggest that OST may be a potential therapeutic agent to minimize inflammation in the several diseases.

Gene expression analysis showed that OST inhibited the expression of $T L R 2, N F-\kappa B$ and $C O X-2$ (Figures 6 and 7). The obtained results suggest that OST suppresses the expression of genes involved in inflammation and reduces the secretion of pro-inflammatory CKs in histamine or LPS-stimulated cells. LPS is known to activate NF-kB and COX-2 signaling in human keratinocyte cell lines, ${ }^{91-94}$ what we also confirmed. Literature indicate that OST exerts antiinflammatory effects via blocking the NF- $\mathrm{KB}$ pathway ${ }^{59}$ and may inhibit histamine $\mathrm{H} 1$ receptor activity and reverse the increase in COX-2 mRNA expression induced by histamine. ${ }^{2}$ Similar results were obtained by Wu in the HepG2 cell line, ${ }^{95}$ where the author showed that OST increased the expression of heme oxygenase 1 , modulated COX-2 and effectively suppressed the secretion of pro-inflammatory CKs. In vitro OST decreased COX-2 expression in LPSstimulated macrophages ${ }^{96}$ and in rat model of sciatica inhibited the expression of COX-2 in the spinal ganglion. ${ }^{97}$ In addition, the author found that OST inhibited inflammation-associated signaling pathways, including NF- $\mathrm{KB}$ and MAP kinases. OST was also shown to alleviate pulmonary arterial hypertension in monocrotaline-treated rats, which is closely associated with disruption of NF- $\mathrm{KB}$ signaling. ${ }^{98} \mathrm{NF}-\mathrm{\kappa B}$ is a multidirectional nuclear transcription factor ${ }^{99}$ and TLRs receptors play a critical role in protecting the host from a variety of exogenous and endogenous pathogens. ${ }^{100,101}$ In response to activation of TLR, NF- $\kappa B$ translocates to the nucleus and induces expression of a numerous genes that mediate immune regulation, cell adhesion and inflammatory response. ${ }^{102}$ NF- $\kappa$ B activates IL- $1 \beta$, IL- 6 , IL- 8 , TNF- $\alpha$, all of which play key roles in the inflammatory response. ${ }^{103}$ When keratinocytes are stimulated via TLRs, these cells produce CKs and ChKs (IL-1 $\beta$, TNF- $\alpha$, GM-CSF, IL-6, and IL-8) as a result of innate immunity function. ${ }^{104,105}$ In the present study, TLR2 expression was constitutively expressed in NHEK and NHDF cell lines, which is consistent with the previously published result. ${ }^{106}$ The final hypothesis we wanted to test was how OST affects wound healing, which is a complex process that includes inflammation, proliferation, and new tissue formation and remodeling. ${ }^{107}$ After skin injury, a cellular response occurs involving fibroblasts, keratinocytes, endothelial cells, and macrophages. ${ }^{108}$ OST significantly improved wound healing in NHEK and NHDF cell lines (Figure 1). Therefore, we hypothesize that OST contributes to tissue normalization at the end of the proliferative phase.

Pattern recognition and transmembrane receptors play a central role in triggering the immune response caused by inflammatory triggers. One of them, TLR2, senses the noxious stimuli and recruits the coordinated activation of transcription factors, including NF- $\mathrm{\kappa B} .{ }^{109}$

Typical triggers of inflammatory signals such as TLR ligands and CKs like TNF- $\alpha$ and IL-1 $\beta$, which are known to activate NF- $\mathrm{KB}$, are translocated to the nucleus and facilitate the transcription of genes encoding pro-inflammatory CKs (IL-1 $\beta$, IL-6, TNF- $\alpha$ ) and chemokines (IL-8, CCL2/MCP-1, CCL5/RANTES) ${ }^{110}$ We hypothesize that OST may act as a regulator of mRNA expression. Therefore, further studies are needed to uncover the molecular basis of its antiinflammatory effect.

We are aware of the limitations of our study, including the lack of signal transduction analysis to confirm the direct link between $T L R 2$, $C O X-2$, and $N F-\kappa B$ signaling. We also plan to perform an in vivo study in a mouse model in the future to confirm our findings.

\section{Conclusion}

In this study, we found that OST suppressed the secretion of CKs and ChKs and the expression of genes encoding TLR2, $N F-\kappa B$ and $C O X-2$ in human keratinocytes and fibroblasts treated with histamine or LPS. OST also had a positive effect 
on cell viability, migration, and barrier function. Our results support the potential use of OST as a therapeutic agent in inflammatory skin diseases caused by bacterial infections and by sudden histamine release due to contact allergies. Moreover, the obtained results confirm the research hypotheses and may be an inspiration for further research, including preclinical and in vitro (3D organotypic skin model) studies allowing to test OST as a blocker of negative immune responses in skin diseases. The use of novel in vitro models has a highly desirable ethical aspect, as the animals used so far are subjected to constant pain and are kept in an unnatural environment. Such treatment of living beings should be kept to a minimum. Understanding the mechanisms of action and interactions of skin cell lines is also crucial for identifying potential molecular targets for future pharmacological interventions to prevent and treat pathological conditions in dermatoses.

\section{Abbreviations}

BrdU, Bromodeoxyuridine; CCL2/MCP-1, the chemokine (C-C motif) ligand 2/ Monocyte Chemoattractant Protein-1; CCL5/RANTES, chemokine (C-C motif) ligand 5/ Regulated on Activation, ChKs, chemokines; CKs, cytokines; COX-2, cyclooxygenase-2; CP, clobetasol propionate; ELISA, enzyme-linked immunosorbent assay FXF, fexofenadine; His, histamine; LPS, lipopolysaccharides; NF-кB, nuclear factor kappa B; NHDF, Normal Human Dermal Fibroblasts; NHEK, Normal Human Epithelial Keratinocytes; OST, osthole, PBMCs, Peripheral blood mononuclear cells; TEER, Transepithelial electrical resistance; TLR, Toll-like receptor; TLR2, Toll-like receptor 2; YWHAZ, Tyrosine 3-Monooxygenase; TCS, topical corticosteroids.

\section{Acknowledgments}

We thank Robert Stryiński from the Department of Biochemistry, Faculty of Biology and Biotechnology, University of Warmia and Mazury, Poland, and Marcin Kutek from the Department of Pathophysiology, Faculty of Medicine, Medical University of Gdańsk, Poland, for an enormous help with English language and style editing.

\section{Funding}

This research was funded by National Science Centre, Poland (2019/03/X/NZ1/01159).

\section{Disclosure}

The authors report no conflicts of interest in this work.

\section{References}

1. Zhang Z-R, Leung WN, Cheung HY, Chan CW. Osthole: a review on its bioactivities, pharmacological properties, and potential as alternative medicine. Evid Based Complement Altern Med. 2015;2015:1-10. doi:10.1155/2015/919616

2. Kordulewska NK, Kostyra E, Cieślińska A, Fiedorowicz E, Jarmołowska B. Cytokine production by PBMC and serum from allergic and non-allergic subjects following in vitro histamine stimulation to test fexofenadine and osthole anti-allergic properties. Eur J Pharmacol. 2016;791:763-772. doi:10.1016/j.ejphar.2016.10.020

3. Wang L, Peng Y, Shi K. Osthole inhibits proliferation of human breast cancer cells by inducing cell cycle arrest and apoptosis. J Biomed Res. 2015;29:132. doi:10.7555/JBR.27.20120115

4. Che Y, Li J, Li Z, et al. Osthole enhances antitumor activity and irradiation sensitivity of cervical cancer cells by suppressing ATM/NF- $\mathrm{kB}$ signaling. Oncol Rep. 2018. doi:10.3892/or.2018.6514

5. Xu X, Liu X, Zhang Y. Osthole inhibits gastric cancer cell proliferation through regulation of PI3K/AKT. PLoS One. 2018;13(3):e0193449. doi:10.1371/journal.pone.0193449

6. Huang R, Chen C, Huang Y, et al. Osthole increases glycosylation of hepatitis B surface antigen and suppresses the secretion of hepatitis B virusin vitro. Hepatology. 1996;24(3):508-515. doi:10.1002/hep.510240307

7. Song F. Experimental study of osthole on treatment of hyperlipidemic and alcoholic fatty liver in animals. World J Gastroenterol. 2006;12 (27):4359. doi:10.3748/wjg.v12.i27.4359

8. Zhang J, Xue J, Wang H, Zhang Y, Xie M. Osthole improves alcohol-induced fatty liver in mice by reduction of hepatic oxidative stress. Phyther Res. 2011;25(5):638-643. doi:10.1002/ptr.3315

9. Jiao Y, Kong L, Yao Y, et al. Osthole decreases beta amyloid levels through up-regulation of miR-107 in Alzheimer's disease. Neuropharmacology. 2016;108:332-344. doi:10.1016/j.neuropharm.2016.04.046

10. Liu W-B, Zhou J, Qu Y, et al. Neuroprotective effect of osthole on MPP+-induced cytotoxicity in PC12 cells via inhibition of mitochondrial dysfunction and ROS production. Neurochem Int. 2010;57(3):206-215. doi:10.1016/j.neuint.2010.05.011

11. Feng X, Zhou H, Zhang Y, et al. Osthole ameliorates simulated microgravity-induced bone loss through down-regulation of miR-34c-5p. Acta Astronaut. 2021;183:141-152. doi:10.1016/j.actaastro.2021.03.015 
12. Kordulewska N, Kostyra E, Matysiewicz M. Cies?li?ska A, Jarmo?owska B. Impact of fexofenadine, osthole and histamine on peripheral blood mononuclear cell proliferation and cytokine secretion. Eur J Pharmacol. 2015;761. doi:10.1016/j.ejphar.2015.05.065

13. Kordulewska NK, Kostyra E, Cieślińska A, Matysiewicz M, Fiedorowicz E, Sienkiewicz-Szłapka E. Changes in gene expression induced by histamine, fexofenadine and osthole: expression of histamine H1 receptor, COX-2, NF-kB, CCR1, chemokine CCL5/RANTES and interleukin$1 \beta$ in PBMC allergic and non-allergic patients. Immunobiology. 2017;222(3):571-581. doi:10.1016/j.imbio.2016.11.004

14. Kordulewska NK, Cieślińska A, Fiedorowicz E, Jarmołowska B, Piskorz-Ogórek K, Kostyra E. Cytokines concentrations in serum samples from allergic children-Multiple analysis to define biomarkers for better diagnosis of allergic inflammatory process. Immunobiology. 2018;223 (11):648-657. doi:10.1016/j.imbio.2018.07.010

15. Kordulewska NK, Kostyra E, Piskorz-Ogórek K, et al. Serum cytokine levels in children with spectrum autism disorder: differences in pro- and anti-inflammatory balance. J Neuroimmunol. 2019;337:577066. doi:10.1016/j.jneuroim.2019.577066

16. Kordulewska NK, Kostyra E, Chwała B, et al. A novel concept of immunological and allergy interactions in autism spectrum disorders: molecular, anti-inflammatory effect of osthole. Int Immunopharmacol. 2019;72:1-11. doi:10.1016/j.intimp.2019.01.058

17. Kordulewska NK, Cieślińska A, Fiedorowicz E, Jarmołowska B, Kostyra E. High Expression of IL-1RI and EP2 Receptors in the IL-1ß/COX-2 Pathway, and a New Alternative to Non-Steroidal Drugs - Osthole in Inhibition COX-2. Int J Mol Sci. 2019;20(1):186. doi:10.3390/ ijms20010186

18. Kordulewska NK, Topa J, Tańska M, et al. Modulatory Effects of Osthole on Lipopolysaccharides-Induced Inflammation in Caco-2 Cell Monolayer and Co-Cultures with THP-1 and THP-1-Derived Macrophages. Nutrients. 2020;13(1):123. doi:10.3390/nu13010123

19. Medzhitov R. Inflammation 2010: new adventures of an old flame. Cell. 2010;140(6):771-776. doi:10.1016/j.cell.2010.03.006

20. Gutsmann T, Razquin-Olazarán I, Kowalski I, et al. New Antiseptic Peptides To Protect against Endotoxin-Mediated Shock. Antimicrob Agents Chemother. 2010;54(9):3817-3824. doi:10.1128/AAC.00534-10

21. Heinbockel L, Sánchez-Gómez S, Martinez de Tejada G, et al. Preclinical Investigations Reveal the Broad-Spectrum Neutralizing Activity of Peptide Pep19-2.5 on Bacterial Pathogenicity Factors. Antimicrob Agents Chemother. 2013;57(3):1480-1487. doi:10.1128/AAC.02066-12

22. Merk VM, Phan TS, Brunner T. Regulation of Tissue Immune Responses by Local Glucocorticoids at Epithelial Barriers and Their Impact on Interorgan Crosstalk. Front Immunol. 2021;12:672808. doi:10.3389/fimmu.2021.672808

23. Celebi Sözener Z, Cevhertas L, Nadeau K, Akdis M, Akdis CA. Environmental factors in epithelial barrier dysfunction. J Allergy Clin Immunol. 2020;145(6):1517-1528. doi:10.1016/j.jaci.2020.04.024

24. Correa-Gallegos D, Jiang D, Rinkevich Y. Fibroblasts as confederates of the immune system. Immunol Rev. 2021;302(1):147-162. doi:10.1111/ imr.12972

25. Buckley CD. Why does chronic inflammation persist: an unexpected role for fibroblasts. Immunol Lett. 2011;138(1):12-14. doi:10.1016/j. imlet.2011.02.010

26. Matthews PM. Chronic inflammation in multiple sclerosis - seeing what was always there. Nat Rev Neurol. 2019;15(10):582-593. doi:10.1038/ s41582-019-0240-y

27. Hanaoka BY, Ithurburn MP, Rigsbee CA, et al. Chronic Inflammation in Rheumatoid Arthritis and Mediators of Skeletal Muscle Pathology and Physical Impairment: a Review. Arthritis Care Res. 2019;71(2):173-177. doi:10.1002/acr.23775

28. Jutel M, Akdis M, Akdis CA. Histamine, histamine receptors and their role in immune pathology. Clin Exp Allergy. 2009;39(12):1786-1800. doi:10.1111/j.1365-2222.2009.03374.x

29. Tiligada E. Editorial: is histamine the missing link in chronic inflammation? J Leukoc Biol. 2012;92(1):4-6. doi:10.1189/jlb.0212093

30. Shim W-S, Oh U. Histamine-induced itch and its relationship with pain. Mol Pain. 2008;4:29. doi:10.1186/1744-8069-4-29

31. Giustizieri ML, Albanesi C, Fluhr J, Gisondi P, Norgauer J, Girolomoni G. H1 histamine receptor mediates inflammatory responses in human keratinocytes. J Allergy Clin Immunol. 2004;114(5):1176-1182. doi:10.1016/j.jaci.2004.07.054

32. Kanda N, Watanabe S. Histamine enhances the production of human beta-defensin-2 in human keratinocytes. Am J Physiol Cell Physiol. 2007;293(6):C1916-23. doi:10.1152/ajpcell.00293.2007

33. Gschwandtner M, Mildner M, Mlitz V, et al. Histamine suppresses epidermal keratinocyte differentiation and impairs skin barrier function in a human skin model. Allergy. 2013;68(1):37-47. doi:10.1111/all.12051

34. Srinivasan B, Kolli AR, Esch MB, Abaci HE, Shuler ML, Hickman JJ. TEER measurement techniques for in vitro barrier model systems. $J$ Lab Autom. 2015;20(2):107-126. doi:10.1177/2211068214561025

35. Dewi T, Muhammad Amir Masruhim RS. Design of three-dimensional collagen matrices for cell delivery and guidance in tissue engineering. Lab Penelit dan Pengemb FARMAKA Trop Fak Farm Univ Mualawarman, Samarinda, Kalimantan Timur. 2016. Available from: https://www. proquest.com/openview/fbb9a5154c4ceac7282384d581693837/1?pq-origsite=gscholar\&cbl=18750. Accessed February 4, 2022.

36. Vega L, Styblo M, Patterson R, Cullen W, Wang C, Germolec D. Differential Effects of Trivalent and Pentavalent Arsenicals on Cell Proliferation and Cytokine Secretion in Normal Human Epidermal Keratinocytes. Toxicol Appl Pharmacol. 2001;172(3):225-232. doi:10.1006/taap.2001.9152

37. Pfaffl MW. A new mathematical model for relative quantification in real-time RT-PCR. Nucleic Acids Res. 2001;29(9):45e- 45. doi:10.1093/nar/ 29.9.e45

38. Sparker CG, Wilson L. The clinical evaluation of a new topical corticosteroid, clobetasol propionate. Br J Dermatol. 1974;90(2):197-203. doi:10.1111/j.1365-2133.1974.tb06385.x

39. Weigmann H-J, Lademann J, Pelchrzim R, et al. Bioavailability of Clobetasol Propionate - quantification of Drug Concentrationsin the Stratum Corneum by Dermatopharmacokinetics UsingTape Stripping. Skin Pharmacol Physiol. 1999;12(1-2):46-53. doi:10.1159/000029845

40. Pahwa R, Jialal I. Hyperglycemia Induces Toll-Like Receptor Activity Through Increased Oxidative Stress. Metab Syndr Relat Disord. 2016;14 (5):239-241. doi:10.1089/met.2016.29006.pah

41. Lawrence T. The nuclear factor NF-kappaB pathway in inflammation. Cold Spring Harb Perspect Biol. 2009;1(6):a001651. doi:10.1101/ cshperspect.a001651

42. Konrath F, Witt J, Sauter T, Kulms D. Identification of new IкB $\alpha$ complexes by an iterative experimental and mathematical modeling approach. PLoS Comput Biol. 2014;10(3):e1003528. doi:10.1371/journal.pcbi.1003528

43. Fang Y, Yang L, He J. Plantanone $C$ attenuates LPS-stimulated inflammation by inhibiting NF- $\mathrm{kB} / \mathrm{iNOS} / \mathrm{COX}-2 / \mathrm{MAPKs} / \mathrm{Akt}$ pathways in RAW 264.7 macrophages. Biomed Pharmacother. 2021;143:112104. doi:10.1016/j.biopha.2021.112104 
44. Radha Kumar M, Puri S. Evaluation of Nutritional, Phytochemical, and Mineral Composition of Selected Medicinal Plants for Therapeutic Uses from Cold Desert of Western Himalaya. Plants. 2021;10(7):1429. doi:10.3390/plants10071429

45. Weidinger S, Beck LA, Bieber T, Kabashima K, Irvine AD. Atopic dermatitis. Nat Rev Dis Prim. 2018;4(1):1. doi:10.1038/s41572-018-0001-z

46. Furue M, Chiba T, Tsuji G, et al. Atopic dermatitis: immune deviation, barrier dysfunction, IgE autoreactivity and new therapies. Allergol Int. 2017;66(3):398-403. doi:10.1016/j.alit.2016.12.002

47. Furue M, Ulzii D, Vu YH, Tsuji G, Kido-Nakahara M, Nakahara T. Pathogenesis of Atopic Dermatitis: current Paradigm. Iran J Immunol. 2019;16(2):97-107. doi:10.22034/IJI.2019.80253

48. Rendon A, Schäkel K. Psoriasis Pathogenesis and Treatment. Int J Mol Sci. 2019;20(6):1475. doi:10.3390/ijms20061475

49. Hammad H, Lambrecht BN. Barrier Epithelial Cells and the Control of Type 2 Immunity. Immunity. 2015;43(1):29-40. doi:10.1016/j. immuni.2015.07.007

50. Zheng R, Chen F-H, Gao W-X, et al. The T H 2-polarizing function of atopic interleukin 17 receptor B-positive dendritic cells up-regulated by lipopolysaccharide. Ann Allergy Asthma Immunol. 2017;118(4):474-482.e1. doi:10.1016/j.anai.2016.12.011

51. Guichard A, Humbert P, Tissot M, Muret P, Courderot-Masuyer C, Viennet C. Effects of topical corticosteroids on cell proliferation, cell cycle progression and apoptosis: in vitro comparison on HaCaT. Int J Pharm. 2015;479(2):422-429. doi:10.1016/j.ijpharm.2014.12.066

52. Gabros S, Nessel TA, Zito PM Topical Corticosteroids; 2021. Available from: http://www.ncbi.nlm.nih.gov/pubmed/30422535. Accessed February 4, 2022.

53. Yasir M, Goyal A, Bansal P, Sonthalia S Corticosteroid Adverse Effects; 2021. Available from: http://www.ncbi.nlm.nih.gov/pubmed/ 30285357. Accessed February 4, 2022.

54. Shenefelt PD Herbal Treatment for Dermatologic Disorders; 2011. Available from: http://www.ncbi.nlm.nih.gov/pubmed/22593930. Accessed February 4, 2022.

55. Patel HK, Barot BS, Parejiya PB, Shelat PK, Shukla A. Topical delivery of clobetasol propionate loaded microemulsion based gel for effective treatment of vitiligo - part II: rheological characterization and in vivo assessment through dermatopharmacokinetic and pilot clinical studies. Colloids Surfaces B Biointerfaces. 2014;119:145-153. doi:10.1016/j.colsurfb.2014.02.005

56. Yuan N, Chen Z, Li L. Narrow-band UVB combined with compound clobetasol propionate can improve the therapeutic effect in hand eczema patients. Am J Transl Res. 2021;13(7):8193-8199.

57. Wu S, Pang Y, He Y, et al. A comprehensive review of natural products against atopic dermatitis: flavonoids, alkaloids, terpenes, glycosides and other compounds. Biomed Pharmacother. 2021;140:111741. doi:10.1016/j.biopha.2021.111741

58. Sun M, Sun M, Zhang J. Osthole: an overview of its sources, biological activities, and modification development. Med Chem Res. 2021;30 (10):1767-1794. doi:10.1007/s00044-021-02775-w

59. Fan H, Gao Z, Ji K, et al. The in vitro and in vivo anti-inflammatory effect of osthole, the major natural coumarin from Cnidium monnieri (L.) Cuss, via the blocking of the activation of the NF-KB and MAPK/p38 pathways. Phytomedicine. 2019;58:152864. doi:10.1016/j. phymed.2019.152864

60. Wu S-J. Osthole Attenuates Inflammatory Responses and Regulates the Expression of Inflammatory Mediators in HepG2 Cells Grown in Differentiated Medium from 3T3-L1 Preadipocytes. J Med Food. 2015;18(9):972-979. doi:10.1089/jmf.2014.3314

61. Joshi P, Singh S, Wani A, et al. Osthol and curcumin as inhibitors of human Pgp and multidrug efflux pumps of Staphylococcus aureus: reversing the resistance against frontline antibacterial drugs. Med Chem Commun. 2014;5(10):1540-1547. doi:10.1039/C4MD00196F

62. Zheng H, Chen Y, Guo Q, et al. Inhibitory Effect of Osthole from Cnidium monnieri (L.) Cusson on Fusarium oxysporum, a Common Fungal Pathogen of Potato. Molecules. 2021;26(13):3818. doi:10.3390/molecules26133818

63. Li L, Wang X, Zhang J-Y, et al. Antifungal activity of osthol in vitro and enhancement in vivo through Eudragit S100 nanocarriers. Virulence. 2018;9(1):555-562. doi:10.1080/21505594.2017.1356503

64. Rashidpour S, Zahedipour F, Karimi G, Jamialahmadi K. Protective Effects of Osthole against Free Radical-Induced Hemolysis of Erythrocytes. Pharm Sci. 2020;27(1):56-62. doi:10.34172/PS.2020.65

65. Huang W-C, Liao P-C, Huang C-H, Hu S, Huang S-C, Wu S-J. Osthole attenuates lipid accumulation, regulates the expression of inflammatory mediators, and increases antioxidants in FL83B cells. Biomed Pharmacother. 2017;91:78-87. doi:10.1016/j.biopha.2017.04.051

66. Gao L, Wang F, Chen Y, Li F, Han B, Liu D. The antithrombotic activity of natural and synthetic coumarins. Fitoterapia. 2021;154:104947. doi:10.1016/j.fitote.2021.104947

67. Liang H-J, Suk F-M, Wang C-K, et al. Osthole, a potential antidiabetic agent, alleviates hyperglycemia in db/db mice. Chem Biol Interact. 2009;181(3):309-315. doi:10.1016/j.cbi.2009.08.003

68. Luszczki JJ, Wojda E, Andres-Mach M, et al. Anticonvulsant and acute neurotoxic effects of imperatorin, osthole and valproate in the maximal electroshock seizure and chimney tests in mice: a comparative study. Epilepsy Res. 2009;85(2-3):293-299. doi:10.1016/j. eplepsyres.2009.03.027

69. Li Y, Sun Z, Xu H, Zhang Q, Zeng C. Osthole inhibits proliferation of kainic acid-activated BV-2 cells by modulating the Notch signaling pathway. Mol Med Rep. 2020. doi:10.3892/mmr.2020.11455

70. Zhang L, Jiang G, Yao F, et al. Growth Inhibition and Apoptosis Induced by Osthole, A Natural Coumarin, in Hepatocellular Carcinoma. PLoS One. 2012;7(5):e37865. doi:10.1371/journal.pone.0037865

71. Mei J, Wang T, Zhao S, Zhang Y. Osthole Inhibits Breast Cancer Progression through Upregulating Tumor Suppressor GNG7. J Oncol. 2021;2021:1-12. doi:10.1155/2021/6610511

72. Stefanachi A, Leonetti F, Pisani L, Catto M, Carotti A. Carotti A. Coumarin: a Natural, Privileged and Versatile Scaffold for Bioactive Compounds. Molecules. 2018;23(2):250. doi:10.3390/molecules23020250

73. Chou S-Y, Hsu C-S, Wang K-T, Wang M-C, Wang -C-C. Antitumor effects of Osthol fromCnidium monnieri: an in vitro and in vivo study Phyther Res. 2007;21(3):226-230. doi:10.1002/ptr.2044

74. Yang LL. Cytotoxic Activity of Coumarins from the Fruits of Cnidium monnieri on Leukemia Cell Lines. Planta Med. 2003;69(12):1091-1095. doi:10.1055/s-2003-45188

75. Jiang G, Liu J, Ren B, et al. Anti-tumor effects of osthole on ovarian cancer cells in vitro. J Ethnopharmacol. 2016;193:368-376. doi:10.1016/j. jep.2016.08.045 
76. Gutzmer R. Pathogenetic and therapeutic implications of the histamine H4 receptor in inflammatory skin diseases and pruritus. Front Biosci. 2011;S3(1):985. doi:10.2741/203

77. Krogstad AL, Lönnroth P, Larson G, Gunnar Wallin B. Increased Interstitial Histamine Concentration in the Psoriatic Plaque. J Invest Dermatol. 1997;109(5):632-635. doi:10.1111/1523-1747.ep12337620

78. Jensen J-M, Fölster-Holst R, Baranowsky A, et al. Impaired Sphingomyelinase Activity and Epidermal Differentiation in Atopic Dermatitis. J Invest Dermatol. 2004;122(6):1423-1431. doi:10.1111/j.0022-202X.2004.22621.x

79. Glatzer F, Gschwandtner M, Ehling S, et al. Histamine induces proliferation in keratinocytes from patients with atopic dermatitis through the histamine 4 receptor. J Allergy Clin Immunol. 2013;132(6):1358-1367. doi:10.1016/j.jaci.2013.06.023

80. Liou C-J, Huang W-C. Dehydroepiandrosterone Suppresses Eosinophil Infiltration and Airway Hyperresponsiveness via Modulation of Chemokines and Th2 Cytokines in Ovalbumin-Sensitized Mice. J Clin Immunol. 2011;31(4):656-665. doi:10.1007/s10875-011-9529-3

81. Han JM, Lee EK, Gong SY, Sohng JK, Kang YJ, Jung HJ. Sparassis crispa exerts anti-inflammatory activity via suppression of TLR-mediated NF-KB and MAPK signaling pathways in LPS-induced RAW264.7 macrophage cells. J Ethnopharmacol. 2019;231:10-18. doi:10.1016/j. jep.2018.11.003

82. Ren J, Li L, Wang Y, Zhai J, Chen G, Hu K. Gambogic acid induces heme oxygenase-1 through Nrf2 signaling pathway and inhibits NF-кB and MAPK activation to reduce inflammation in LPS-activated RAW264.7 cells. Biomed Pharmacother. 2019;109:555-562. doi:10.1016/j. biopha.2018.10.112

83. Lee -H-H, Jang E, Kang S-Y, et al. Anti-inflammatory potential of Patrineolignan B isolated from Patrinia scabra in LPS-stimulated macrophages via inhibition of NF-kB, AP-1, and JAK/STAT pathways. Int Immunopharmacol. 2020;86:106726. doi:10.1016/j. intimp.2020.106726

84. Joung E-J, Cao L, Lee B, Gwon W-G, Park S-H, Kim H-R. Sargahydroquinoic Acid, a Cyclooxygenase-2 Inhibitor, Attenuates Inflammatory Responses by Regulating NF- $\mathrm{BB}$ Inactivation and Nrf2 Activation in Lipopolysaccharide-Stimulated Cells. Inflammation. 2021;44 (5):2120-2131. doi:10.1007/s10753-021-01488-x

85. Kang J-K, Chung Y-C, Hyun C-G. Anti-Inflammatory Effects of 6-Methylcoumarin in LPS-Stimulated RAW 264.7 Macrophages via Regulation of MAPK and NF-кB Signaling Pathways. Molecules. 2021;26(17):5351. doi:10.3390/molecules26175351

86. Kim NY, Cheong SH, Lee KJ, Sok D-E, Kim MR. Anti-Inflammatory Effects of Ribes diacanthum Pall Mediated via Regulation of Nrf2/HO-1 and NF-кB Signaling Pathways in LPS-Stimulated RAW 264.7 Macrophages and a TPA-Induced Dermatitis Animal Model. Antioxidants. 2020;9(7):622. doi:10.3390/antiox9070622

87. Li R, Song P, Tang G, et al. Osthole Attenuates Macrophage Activation in Experimental Asthma by Inhibiting the NF-KB/MIF Signaling Pathway. Front Pharmacol. 2021:12. doi:10.3389/fphar.2021.572463.

88. Singh L, Kaur A, Garg S, Bhatti R. Skimmetin/osthole mitigates pain-depression dyad via inhibiting inflammatory and oxidative stress-mediated neurotransmitter dysregulation. Metab Brain Dis. 2021;36(1):111-121. doi:10.1007/s11011-020-00604-4

89. Li F, Gong Q, Wang L, Shi J. Osthole attenuates focal inflammatory reaction following permanent middle cerebral artery occlusion in rats. Biol Pharm Bull. 2012;35(10):1686-1690. doi:10.1248/bpb.b12-00133

90. Yu C, Li P, Qi D, et al. Osthole protects sepsis-induced acute kidney injury via down-regulating NF-אB signal pathway. Oncotarget. 2017;8 (3):4796-4813. doi:10.18632/oncotarget.13592

91. Pivarcsi A, Koreck A, Bodai L, et al. Differentiation-regulated expression of Toll-like receptors 2 and 4 in HaCaT keratinocytes. Arch Dermatol Res. 2004;296(3):120-124. doi:10.1007/s00403-004-0475-2

92. Su SB, Silver PB, Grajewski RS, et al. Essential Role of the MyD88 Pathway, but Nonessential Roles of TLRs 2, 4, and 9, in the Adjuvant Effect Promoting Th1-Mediated Autoimmunity. J Immunol. 2005;175(10):6303-6310. doi:10.4049/jimmunol.175.10.6303

93. Lim H-J, Jie EY, Park I-S, et al. Anti-Inflammatory Effects of Weigela subsessilis Callus Extract via Suppression of MAPK and NF-kB Signaling. Plants. 2021;10(8):1635. doi:10.3390/plants10081635

94. Chang J, Wang L, Zhang M, Lai Z. Glabridin attenuates atopic dermatitis progression through downregulating the TLR4/MyD88/NF- $\mathrm{BB}$ signaling pathway. Genes Genomics. 2021;43(8):847-855. doi:10.1007/s13258-021-01081-4

95. Zhang L, Jiang G, Yao F, et al. Osthole promotes anti-tumor immune responses in tumor-bearing mice with hepatocellular carcinoma. Immunopharmacol Immunotoxicol. 2015;37(3):301-307. doi:10.3109/08923973.2015.1035391

96. Nakamura T, Kodama N, Arai Y, et al. Inhibitory effect of oxycoumarins isolated from the Thai medicinal plant Clausena guillauminii on the inflammation mediators, iNOS, TNF-alpha, and COX-2 expression in mouse macrophage RAW 264.7. J Nat Med. 2009;63(1):21-27. doi:10.1007/s11418-008-0277-5

97. Wei M, Zhang -J-J, He Q-L, et al. [Effects and mechanisms of osthole on sciatica induced by lumber disc herniation]. Zhong Yao Cai. 2011;34 (5):746-750. Journal of Chinese medicinal materials.

98. Li Y, Wang Y, Li Y, Qian Z, Zhu L, Yang D. Osthole attenuates pulmonary arterial hypertension in monocrotaline-treated rats. Mol Med Rep. 2017;16(3):2823-2829. doi:10.3892/mmr.2017.6876

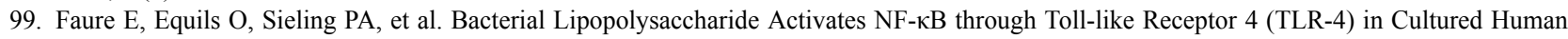
Dermal Endothelial Cells. J Biol Chem. 2000;275(15):11058-11063. doi:10.1074/jbc.275.15.11058

100. Lazaridis A, Gavriilaki E, Douma S, Gkaliagkousi E. Toll-like receptors in the pathogenesis of essential hypertension. a forthcoming immune-driven theory in full effect. Int J Mol Sci. 2021;22(7):3451. doi:10.3390/ijms22073451

101. Banerjee S. Emerging roles of microRNAs in the regulation of Toll-like receptor (TLR)-signaling. Front Biosci. 2021;26(4):4917. doi:10.2741/ 4917

102. Hayden MS, Ghosh S. NF- B, the first quarter-century: remarkable progress and outstanding questions. Genes Dev. 2012;26(3):203-234. doi:10.1101/gad.183434.111

103. Sun W, Gao Y, Yu X, et al. 'Psoriasis 1' reduces psoriasis-like skin inflammation by inhibiting the VDR-mediated nuclear NF- $\kappa B$ and STAT signaling pathways. Mol Med Rep. 2018. doi:10.3892/mmr.2018.9262

104. Sugita K, Kabashima K, Atarashi K, Shimauchi T, Kobayashi M, Tokura Y. Innate immunity mediated by epidermal keratinocytes promotes acquired immunity involving Langerhans cells and T cells in the skin. Clin Exp Immunol. 2006;61120065600003. doi:10.1111/j.13652249.2006.03258.x 
105. Kawai K. Expression of functional toll-like receptors on cultured human epidermal keratinocytes. J Invest Dermatol. $2003 ; 121(1): 217$. doi:10.1046/j.1523-1747.2003.12305.x

106. Yao C, Oh J-H, Lee DH, et al. Toll-like receptor family members in skin fibroblasts are functional and have a higher expression compared to skin keratinocytes. Int J Mol Med. 2015;35(5):1443-1450. doi:10.3892/ijmm.2015.2146

107. Monsuur HN, Boink MA, Weijers EM, et al. Methods to study differences in cell mobility during skin wound healing in vitro. $J$ Biomech. 2016;49(8):1381-1387. doi:10.1016/j.jbiomech.2016.01.040

108. Alerico GC, Beckenkamp A, Vignoli-Silva M, Buffon A, von Poser GL. Proliferative effect of plants used for wound healing in Rio Grande do Sul state, Brazil. J Ethnopharmacol. 2015;176:305-310. doi:10.1016/j.jep.2015.11.001

109. Mukherjee S, Karmakar S, Babu SPS. TLR2 and TLR4 mediated host immune responses in major infectious diseases: a review. Brazilian J Infect Dis. 2016;20(2):193-204. doi:10.1016/j.bjid.2015.10.011

110. Liu T, Zhang L, Joo D, Sun S-C. NF-אB signaling in inflammation. Signal Transduct Target Ther. 2017;2:e17023. doi:10.1038/sigtrans.2017.23

Journal of Inflammation Research

\section{Publish your work in this journal}

The Journal of Inflammation Research is an international, peer-reviewed open-access journal that welcomes laboratory and clinical findings on the molecular basis, cell biology and pharmacology of inflammation including original research, reviews, symposium reports, hypothesis formation and commentaries on: acute/chronic inflammation; mediators of inflammation; cellular processes; molecular mechanisms; pharmacology and novel anti-inflammatory drugs; clinical conditions involving inflammation. The manuscript management system is completely online and includes a very quick and fair peer-review system. Visit http://www.dovepress.com/testimonials.php to read real quotes from published authors.

Submit your manuscript here: https://www.dovepress.com/journal-of-inflammation-research-journal 